\title{
Identification of Tropical-Extratropical Interactions and Extreme Precipitation Events in the Middle East based on Potential Vorticity and Moisture Transport
}

Authors: A.J. de Vries ${ }^{1}$, H.G. Ouwersloot ${ }^{1}$, S.B. Feldstein ${ }^{2}$, M. Riemer ${ }^{3}$, A.M. El Kenawy ${ }^{4}$, M.F. McCabe $^{5}$, J. Lelieveld ${ }^{1,6}$

1) Atmospheric Chemistry Department, Max Planck Institute for Chemistry, Mainz, Germany

$\left.{ }^{2}\right)$ Department of Meteorology, The Pennsylvania State University, University Park, USA

${ }^{3}$ ) Institut für Physik der Atmosphäre, University of Mainz, Germany

$\left.{ }^{4}\right)$ Department of Geography, Mansoura University, Egypt

5 ) Water Desalination and Reuse Center, Division of Biological and Environmental Sciences and Engineering, King Abdullah University of Science and Technology, Jeddah, Saudi Arabia

$\left.{ }^{6}\right)$ Energy, Environment and Water Research Center, The Cyprus Institute, Nicosia, Cyprus

Corresponding author: A.J. de Vries (a.devries@mpic.de)

Key Points:

- We combine stratospheric PV intrusions and poleward IVT structures for identification of extreme precipitation in the Middle East

- IVT is a potentially more pertinent predictor for extreme precipitation than PV

- Tropical-extratropical interactions contribute to a large fraction of the climatological rainfall amounts and extreme precipitation days

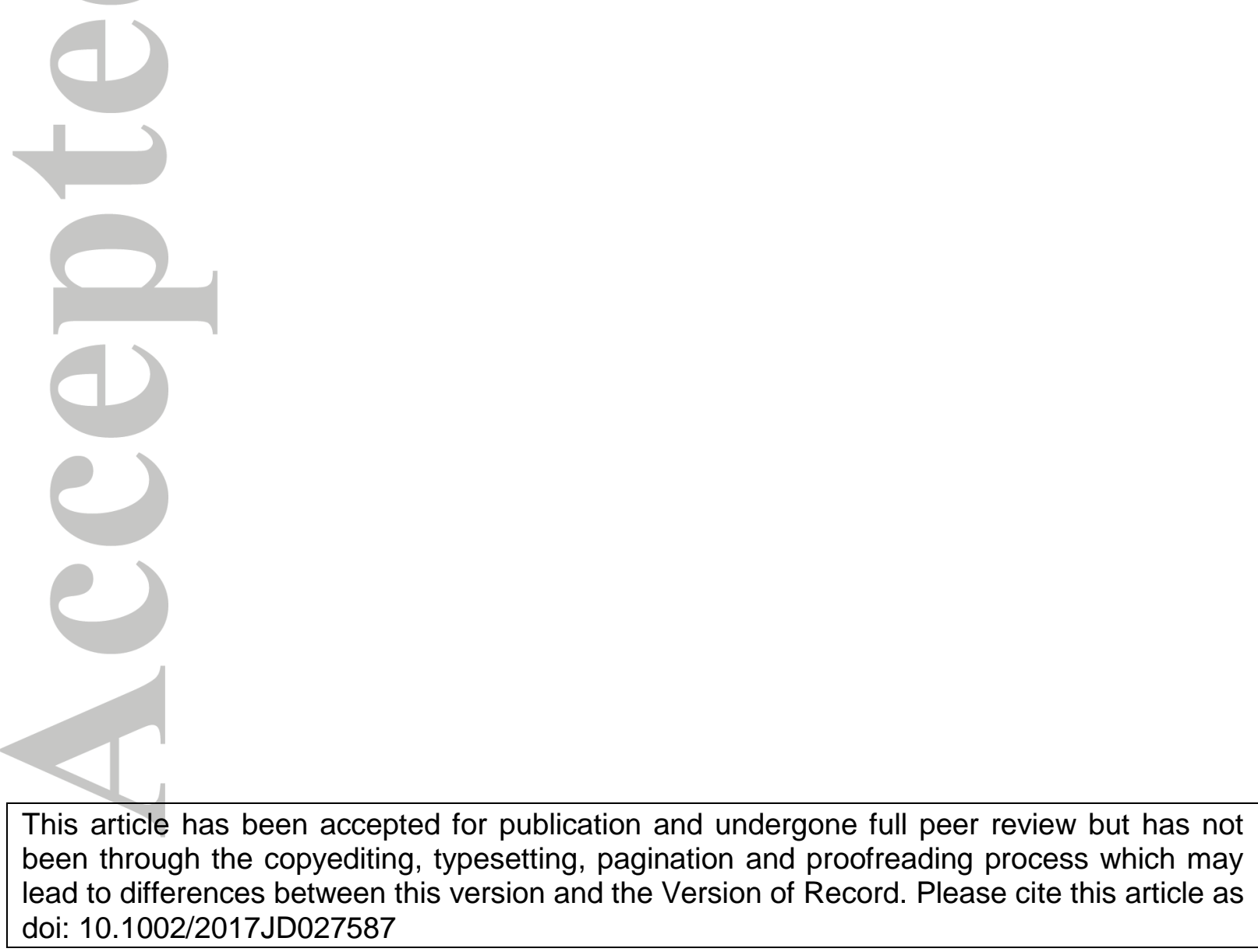

(C) 2017 American Geophysical Union. All rights reserved. 


\begin{abstract}
Extreme precipitation events in the otherwise arid Middle East can cause flooding with dramatic socioeconomic impacts. Most of these events are associated with tropical-extratropical interactions, whereby a stratospheric potential vorticity (PV) intrusion reaches deep into the subtropics and forces an incursion of high poleward vertically integrated water vapor transport (IVT) into the Middle East. This study presents an object-based identification method for extreme precipitation events based on the combination of these two larger-scale meteorological features. The general motivation for this approach is that precipitation is often poorly simulated in relatively coarse weather and climate models, whereas the synoptic-scale circulation is much better represented. The algorithm is applied to ERA-Interim reanalysis data $(1979-2015)$ and detects $90 \%(83 \%)$ of the $99^{\text {th }}\left(97.5^{\text {th }}\right)$ percentile of extreme precipitation days in the region of interest. Our results show that stratospheric PV intrusions and IVT structures are intimately connected to extreme precipitation intensity and seasonality. The farther south a stratospheric PV intrusion reaches, the larger the IVT magnitude, and the longer the duration of their combined occurrence, the more extreme the precipitation. Our algorithm detects a large fraction of the climatological rainfall amounts (40-70\%), heavy precipitation days (50-80\%), and the top 10 extreme precipitation days (60-90\%) at many sites in southern Israel and the northern and western parts of Saudi Arabia. This identification method provides a new tool for future work to disentangle teleconnections, assess medium-range predictability and improve understanding of climatic changes of extreme precipitation in the Middle East and elsewhere.

Index terms: precipitation (3354/1854), synoptic-scale meteorology (3364), extreme events (1817/4313), floods (1821/4303), climatology (3309)
\end{abstract}

Keywords: heavy rainfall, algorithm, stratospheric intrusions, integrated vapor transport, Rossby wave breaking, atmospheric rivers

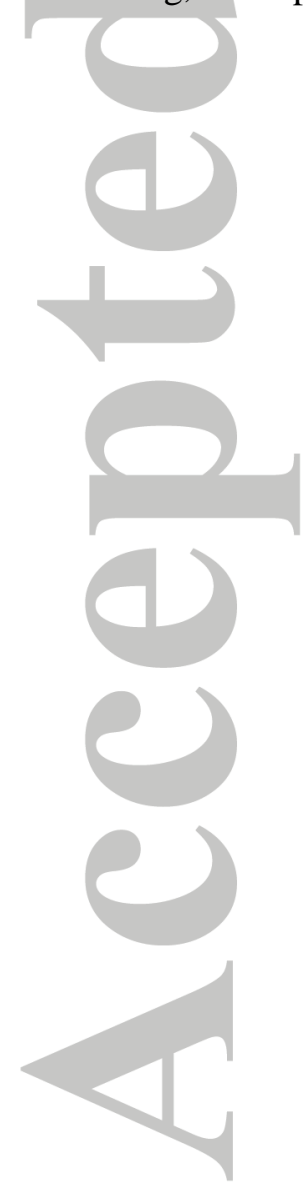




\section{Introduction}

Extreme precipitation events in the otherwise arid Middle East can have dramatic socioeconomic impacts. In Egypt, Israel, Jordan and Saudi Arabia, 39 flood events over the period of 1900-2016 caused 1,508 fatalities, affected 291,387 people, and resulted in damages exceeding 1.8 billion US dollars (Emergency Events Database, unpublished data, provided on 19 April 2017 by the Centre for Research on the Epidemiology of Disasters; CRED). At the same time, these recurrent rainfall events replenish scarce fresh water resources that are crucial for agriculture [Amin et al., 2016; Schulz et al., 2016]. Therefore, the understanding of extreme precipitation events in the Middle East, their predictability and changes due to global warming are of high interest.

Extreme precipitation events in the Middle East often result from tropical-extratropical interaction, whereby midlatitude forcing and poleward transport of tropical moisture are of central importance (Figure 1a). Case studies of such events revealed the intrusion of a midlatitude upper-level trough into the subtropics, which interacts with the tropical low-level circulation and initiates an incursion of tropical moisture into the region [De Vries et al., 2013, 2016]. Also, from a climatological perspective, heavy rainfall over the Middle East is typically associated with an upper-level cyclonic circulation and enhanced southerly moisture fluxes [Kahana et al., 2004; Evans and Smith, 2006; Krichak et al., 2012; Kumar et al., 2015; Almazroui et al., 2016]. Apart from the Middle East, tropical-extratropical interactions and extreme precipitation events also affect arid subtropical regions elsewhere, including northwestern Africa, southwestern North America, southern Africa, Pakistan, the Himalaya's, and Australia [Wright, 1997; Knippertz et al., 2003; Favors and Abatzoglou, 2013; Hart et al., 2010; Martius et al., 2013; Vellore et al., 2016].

Previous studies have presented various identification methods for atmospheric features that have direct relevance to tropical-extratropical interactions and/or extreme precipitation. These include cloud bands or tropical plumes based on satellite imagery [Hart et al., 2012, 2013; Frölich et al., 2013], tropical moisture exports [Knippertz 2003, Knippertz and Wernli, 2010; Knippertz et al., 2013] and warm conveyor belts [Madonna et al., 2014b; Pfahl et al., 2014] using trajectories, moisture surges or monsoon bursts through applying statistically-based thresholds on moisture flux and wind fields [Cavazos et al., 2002; Favors and Abatzoglou, 2013; Pascale and Bordoni, 2016], and atmospheric rivers. Atmospheric rivers have received increased attention over the last decade as they are a key feature in heavy rainfall and flooding across North America and Europe [e.g. Ralph et al., 2006; Lavers and Villarini, 2013a, 2013b; Waliser and Guan, 2017]. They are characterized by narrow and elongated plume-like structures of strong moisture transport and their features are often detected using vertically integrated water vapor fluxes (IVT) [e.g. Rutz et al., 2014; Guan and Waliser, 2015; Mahoney et al., 2016; Mundhenk et al., 2016a]. Besides application for identification of atmospheric rivers, IVT is also widely recognized as a large-scale precursor, environmental characteristic, and medium-range predictor of extreme precipitation occurrence [e.g. Lavers et al., 2014; Moore et al., 2015; Froidevaux and Martius, 2016]. Furthermore, several case studies and climatological investigations adopted IVT to identify moisture pathways associated with extreme precipitation events [e.g. Knippertz et al., 2003; Swales et al., 2016].

Another atmospheric feature that has our specific interest are stratospheric potential vorticity (PV) intrusions, which have been identified as precursors of extreme precipitation in the Alpine region, southern Africa, and northwestern Africa [Massacand et al., 1998; Knippertz and Martin, 2005; Hart et al., 2010]. Martius et al. (2006) presented climatological evidence for the relationship between objectively identified stratospheric PV intrusions and extreme precipitation in the southern Alps. Also, heavy rainfall in the Middle East has been associated with upper-tropospheric PV anomalies 
[Evans and Smith, 2006; Kumar et al. 2015; De Vries et al., 2016]. Stratospheric PV intrusions can drive convection and extreme precipitation through (i) reducing the static stability in the lower troposphere and building up convective potential available energy (CAPE), (ii) inducing dynamical lifting ahead of the PV anomaly, (iii) transporting moisture on its downstream flank, and (iv) orographic lifting through orienting the low-level winds toward a topographic barrier [Funatsu and Waugh, 2008; Schlemmer et al., 2010; Martius et al., 2013]. In addition, stratospheric PV intrusions can also indirectly contribute to the formation of extreme precipitation in subtropical regions when they extend far into low latitudes, interact with the tropical low-level circulation, and thus pave the way for a tropical moisture excursion [Knippertz, 2007]. Although the importance of both stratospheric PV intrusions and high moisture fluxes for heavy rainfall has been recognized in several studies [Evans and Smith, 2006; Martius et al., 2006; Barton et al., 2016; Froidevaux and Martius, 2016], they have thus far not been combined in an algorithm for the identification of extreme precipitation events.

In this study, we present for the first time an object-based identification method for extreme precipitation events based on the combination of stratospheric PV intrusions and structures of high IVT. The motivations for this approach are threefold: (1) Stratospheric PV intrusions and IVT structures represent the midlatitude forcing and tropical moisture contributions, respectively, of tropical-extratropical interactions, (2) PV and IVT are both larger-scale meteorological precursors of extreme precipitation, and (3) the novelty of combining these features in an algorithm for the detection of extreme precipitation. The aim of this approach is to identify extreme precipitation events without using precipitation data themselves, which are often subject to limitations of relatively coarse resolution model simulations or the observational data products [e.g. Zhang et al., 2011; Donat et al., 2014]. In contrast, the synoptic-scale circulation in meteorological data sets is much better represented, which introduces the perspective to apply the algorithm on long-term reanalysis data sets and climate model output in future studies.

The organization of the paper is as follows. Section 2 describes the employed data sets, the definition of extreme precipitation days, and the algorithm for identifying stratospheric PV intrusions and IVT structures. Next, we apply the algorithm to the Middle East region using reanalysis data (section 3) and we investigate the importance of PV and IVT for extreme precipitation events in a climatological context (section 4). Furthermore, section 5 addresses the relation between the PV and IVT characteristics and the severity of the precipitation. Finally, we quantify the contribution of the tropical-extratropical interactions to climatological rainfall amounts and extreme precipitation days in the Middle East using observational precipitation data (section 6). Section 7 presents the conclusions and some implications of the study.

\section{Data and Methods}

\subsection{Reanalysis and Observational Precipitation Data}

We employed 6-hourly ERA-Interim reanalysis data on a N128 Gaussian grid $\left(\sim 0.7^{\circ} \mathrm{x} 0.7^{\circ}\right)$ for the period 1979-2015 [Dee et al., 2011] to identify stratospheric PV intrusions and IVT structures. Zonal and meridional IVT fields are available and PV was computed from data on model levels and then linearly interpolated onto isentropic levels between 295 and $370 \mathrm{~K}$, with $5 \mathrm{~K}$ intervals. Figure 2a presents an example of PV on an isentropic surface and the full IVT field.

Furthermore, we used precipitation from reanalysis, gridded observational, satellite-based and individual station data to examine the contribution of the stratospheric PV intrusions and IVT 
structures to the climatological precipitation amounts and extreme precipitation days. Each precipitation data set has its strengths and limitations, motivating us to use a variety of different data sources. Daily precipitation from ERA-Interim data was constructed from 12-hourly accumulated forecasts from 00 and 12 UTC. Aphrodite (V1101) contains gridded daily precipitation, based on station data, with a spatial resolution of $0.25^{\circ} \times 0.25^{\circ}$, spanning the years 1951-2007 [Yatagai et al., 2012]. Also, we used daily rainfall data of the 3B42 version 7 product of the Tropical Rainfall Measuring Mission Multisatellite Precipitation Analysis (hereafter TRMM), with a $0.25^{\circ} \times 0.25^{\circ}$ spatial resolution, available from 1998 to the present [Huffman et al., 2007]. Note that we limit the analysis for this particular data set until 2013 as the TRMM satellite was decommissioned in 2014. Furthermore, we used daily rainfall records from stations in Saudi Arabia and Israel. For Saudi Arabia, the data set presented by El Kenawy and McCabe [2016] provides ground-based observations, comprising 240 individual daily rainfall records spanning 1979 to 2012 . We only used time series with less than $50 \%$ missing values, resulting in 192 daily rainfall records. Station data from Israel were provided by the Israel Meteorological Service (IMS). We used 158 rainfall records that covered at least 20 years of the 37-year period of 1979-2015. Daily observations with flags indicating that the rainfall amount may be interpolated or accumulated over multiple days were treated as missing values.

\subsection{Definitions of Extreme Precipitation Days}

The region of interest encompasses eastern Egypt, southern Israel, Jordan, and the northern and western parts of Saudi Arabia (depicted by the black box in Figure 1b), where extreme precipitation events with devastating impacts have been recurrent. This area covers the arid subtropical desert region with very low annual rainfall amounts between the wetter eastern Mediterranean to the northwest and the tropical rain belt to the south. Previous studies adopted varying definitions of extreme precipitation ranging from straightforward percentile-based thresholds on individual grid points or area-averaged precipitation [Martius et al., 2006; Pfahl and Wernli, 2012; Favors and Abatzoglou, 2013; Skerlak et al., 2015] to more sophisticated methods such as object-based approaches [Moore et al., 2015; Mahoney et al., 2016]. Since the available reanalysis and observational data are subject to several limitations, we opted for a relatively simple and straightforward approach. We define extreme precipitation days (EPDs) by the $99^{\text {th }}$ and $97.5^{\text {th }}$ percentile of daily precipitation in ERA-Interim data, averaged over the grid points in the black box in Figure 1b. This definition of EPDs is rather crude and can include both localized heavy rainfall and less intense, widespread rainfall. Both types of events are of interest here as precipitation in the dry desert region has by nature an extreme character. Throughout this study we will mostly use the $97.5^{\text {th }}$ percentile EPDs, as these include all relevant extreme precipitation events as identified by visual inspection of daily precipitation in ERA-Interim, Aphrodite and TRMM data.

The use of precipitation data from ERA-Interim for EPDs introduces a potential constraint in that it is the same data set as for which we apply the algorithm, and that localized heavy rainfall may not be adequately resolved, but it has the advantage of suitable spatial and temporal coverage. Available observational data sets do not cover the extended period of 1979-2015 under consideration (Aphrodite and TRMM), underestimate rainfall amounts (Aphrodite, see Tanarhte et al. [2012]), and suffer from a relatively poor-density station network (Aphrodite and stations) and limited availability in the region of interest (stations). To evaluate the fidelity of using ERA-Interim data for defining EPDs, we compare these to EPDs derived from Aphrodite and TRMM, after interpolating the data from the regular $0.25^{\circ} \times 0.25^{\circ}$ grid to a N128 Gaussian grid, for the time period that is covered by all three data sets (1998-2007). Of the $99^{\text {th }}\left(97.5^{\text {th }}\right)$ percentile EPDs in ERA-Interim data, 79\% (71\%) matches with EPDs in Aphrodite or TRMM data, indicating a reasonable representativeness of the EPDs using 
ERA-Interim data. Also, Pfahl and Wernli [2012] demonstrated in their Figure 3 a reasonable agreement between 6-hourly $99^{\text {th }}$ percentile precipitation in ERA-Interim and the Climate Prediction Center morphing method $(\mathrm{CMORPH})$, ranging from $>50 \%$ over eastern Egypt up to $>90 \%$ over the northwestern portions of Saudi Arabia.

\subsection{Algorithm for PV Intrusions and IVT Structures}

We identify PV intrusions following Wernli and Sprenger [2007] and Sprenger et al. [2013]. This approach has been adopted by many studies addressing the climatological characteristics and representation of PV intrusions in global circulation models [Martius et al., 2008a; Isotta et al., 2008; Beguin et al., 2013], and their relation to extreme weather events, warm conveyor belts, and the exchange of tropical-extratropical and stratospheric-tropospheric air masses [Martius et al., 2006; 2008b; Sprenger et al., 2007, 2013; Madonna et al., 2014a; Kunz et al., 2015]. Following the approach of Wernli and Sprenger [2007] and Sprenger et al. [2013], we consider the 2 potential vorticity unit (PVU; $1 \mathrm{PVU}=10^{-6} \mathrm{~K} \mathrm{~kg}^{-1} \mathrm{~m}^{2} \mathrm{~s}^{-1}$ ) surface as the dynamical tropopause, separating the stratospheric (PV>2 PVU) and tropospheric (PV $<2 \mathrm{PVU}$ ) air masses (Figure 2). The $2 \mathrm{PVU}$ contours on isentropic surfaces serve to identify PV intrusions, which are indicators of Rossby wave breaking. These PV contours can form narrow and elongated filaments (PV streamers) and can split off from the main stratospheric or tropospheric reservoirs (PV cutoffs). This specific method has advantages over other approaches that consider stratospheric PV intrusions from a vertical perspective or by overturning of PV contours in the meridional direction on the quasi-horizontal plane. The former approach refers to multiple crossings of the dynamical tropopause in vertical profiles, so-called tropopause folds, which have been associated with the occurrence of extreme precipitation [Skerlak et al., 2015]. However, as these authors remarked, the precipitation is related to the larger-scale trough in which the fold is embedded, rather than the mesoscale fold itself, motivating our choice to identify stratospheric PV intrusions on a quasi-horizontal plane. In the latter approach, meridionally overturning PV contours serve as an indicator of Rossby wave breaking [e.g. McIntyre and Palmer, 1983; Strong and Magnusdottir, 2008; Liu et al., 2014]. This implies that meridionally elongated PV streamers without meridional overturning of PV contours would be ignored, although such stratospheric PV intrusions can be important for extreme precipitation, further supporting our choice to identify PV intrusions using the method of Wernli and Sprenger [2007] and Sprenger et al. [2013]. For the sake of clarity, we describe our reproduced algorithm with special emphasis on a few modifications.

The algorithm is applied on isentropic surfaces between $300-350 \mathrm{~K}$ with $5 \mathrm{~K}$ intervals and consists of the following four steps. First, at each 6-hourly time instance and on each isentropic surface, we retrieve the +2 PVU contour and the contour point coordinates (Figures 1a and 2). Accordingly, only PV intrusions relevant to the Northern Hemisphere are considered. The coordinates of the $2 \mathrm{PVU}$ contour points are determined by a visualization routine of the National Center for Atmospheric Research (NCAR) Command Language (NCL) package version 6.3.0 that is designed to draw contour lines. Second, the stratospheric body is determined, which corresponds to the extensive reservoir of stratospheric air mass that covers higher latitudes (Figure 2b). To this end, we select the $2 \mathrm{PVU}$ contour with the lowest latitude that encircles the northern hemisphere. If such a contour is not available, we appoint the longest $2 \mathrm{PVU}$ contour that has a zonal extent $>180^{\circ}$ and at least one contour point $>80^{\circ} \mathrm{N}$ as the stratospheric body. In case such a contour is also not available, the PV streamer identification is not applied. All remaining 2 PVU contours are considered as PV cutoffs. Third, for the identification of PV streamers, we evaluate for each pair of contour points of the stratospheric body, the geometrical criteria of the potential streamer; the width (W), length (L), and ratio (r) of $\mathrm{L}$ over $\mathrm{W}$ (Figure 1a). The width of the potential streamer is defined as the great-circle 
distance (shortest distance between two points on a sphere, measured over the surface of the sphere) between the contour points A and B. To determine the length of the potential streamer, we evaluate the shortest great-circle distances of all contour points between points $\mathrm{A}$ and $\mathrm{B}$ (for example, point $\mathrm{C}$ in Figure 1a) to the great circle defined by points A and B (point D in Figure 1a). The largest of these great-circle distances is defined as the length of the potential streamer. Fourth, all grid points within the polygons of the PV streamers and cutoffs are classified as being stratospheric (PV>2 PVU) or tropospheric ( $\mathrm{PV}<2 \mathrm{PVU}$ ) intrusions. Figure $2 \mathrm{~b}$ illustrates the successful identification of complex PV intrusion structures such as double, triple or multiple neighboring streamers (over Europe, the Pacific Ocean, and Asia, respectively), a streamer being encapsulated within another streamer (to the east of the Caspian Sea), and cutoffs being located within streamers (to the north and east of the Caspian Sea).

Our streamer length definition deviates from Wernli and Sprenger [2007] and Sprenger et al. [2013], who used the contour length between points A and B. We define the length of the PV streamer, perpendicular to the great circle of points $\mathrm{A}$ and $\mathrm{B}$ to introduce a more appropriate geometrical length measure of the PV streamers and to avoid features with wriggles and twisted contour lines. To evaluate the skill of the previous and new geometrical streamer definitions to detect EPDs, we perform sensitivity tests with both streamer definitions and various thresholds, and quantify the coincidences between EPDs and days with stratospheric PV intrusions (i.e. PV incursions, for their definition, see section 3.3). More specifically, we use measures of the contingency matrix and calculate the EPD hits (EPDs coinciding with PV incursions divided by all EPDs) and false alarm ratios (PV incursions coinciding with $<95^{\text {th }}$ percentile precipitation days, divided by all PV incursions; Table 1). Our new streamer definition outperforms that applied in Wernli and Sprenger [2007] and reaches about equal scores as that applied in Sprenger et al. [2013] for extreme precipitation events in the Middle East. For example, the streamer criteria of the latter study (W<1500km, contour length $>2000 \mathrm{~km}$, and $\mathrm{r}>2$ ) coincides with $93.4 \%$ of the $99^{\text {th }}$ percentile EPDs and $90.0 \%$ of the $97.5^{\text {th }}$ percentile EPDs, and had a false alarm ratio of $89.8 \%$ (Table 1). These scores are close to our new PV streamer geometry with thresholds of $\mathrm{W}<1500 \mathrm{~km}, \mathrm{~L}>650 \mathrm{~km}$ and $\mathrm{r}>0.65$, and show a slight deterioration for the $99^{\text {th }}$ percentile EPDs (92.0\%), and a slight improvement with regard to the $97.5^{\text {th }}$ percentile EPDs (90.3\%) as well as the false alarm ratio (89.6\%). Throughout the remainder of this article we use the PV streamer thresholds $\mathrm{W}<1500 \mathrm{~km}, \mathrm{~L}>650 \mathrm{~km}$, and $\mathrm{r}>0.65$ unless mentioned otherwise.

IVT structures are defined as all grid points with a positive meridional (northward directed) IVT $>200$ $\mathrm{kg} \mathrm{m}^{-1} \mathrm{~s}^{-1}$ (Figure 2b). Here, we use the meridional component of the IVT instead of the full IVT field as we are particularly interested in the poleward moisture transport. Most studies on the identification of atmospheric rivers adopted static thresholds on IVT or anomalous IVT that typically range between 250 and $500 \mathrm{~kg} \mathrm{~m}^{-1} \mathrm{~s}^{-1}$ [Payne and Magnusdottir, 2014; Rutz et al., 2014; Mahoney et al., 2016;

Mundhenk et al., 2016a]. We apply a somewhat lower threshold of $200 \mathrm{~kg} \mathrm{~m}^{-1} \mathrm{~s}^{-1}$ since we adopt only the meridional IVT component and to adjust to the lower background moisture transport in the Middle East region.

In the final stage, we retrieve unique characteristics of all individual PV and IVT features. These include, for example, the southward extent of stratospheric PV intrusions and the magnitude of the IVT structures, defined by the minimum latitude of the stratospheric PV intrusions and the maximum IVT value of the IVT structures, respectively. Furthermore, we reject (1) relatively small PV intrusions and IVT structures with a surface area $<100,000 \mathrm{~km}^{2}$ (for example, the tropospheric PV cutoff over the North Pole and the IVT structure over the southern Red Sea in Figure 2), (2) all PV streamers if $>50 \%$ of the stratospheric body consists of stratospheric PV streamers, and (3) cutoffs if 
any grid point within the structure on the isentropic surface is below the surface topography (for example, the stratospheric cutoff over the Himalaya's in Figure 2). The first criterion aims to retain only larger-scale features. The second criterion prevents the larger part of the stratospheric body from being a PV streamer when the 2 PVU contour is very distorted, similar to the $80 \%$ threshold of the contour length of the stratospheric body used by Sprenger et al. [2013]. The third criterion removes a part of the 'stratospheric' PV cutoffs that are associated with frictional processes near topography rather than with intrusions of stratospheric air masses.

\subsection{Examples of Extreme Precipitation Cases}

Figure 3 demonstrates the functionality of the algorithm in four cases of extreme precipitation in the Middle East that resulted in flooding and severe societal impacts. In each case we find a stratospheric PV intrusion over northeast Africa accompanied by an IVT structure on its eastern flank. This meteorological configuration reflects Rossby wave breaking along with a midlatitude upper-level trough that intrudes into the subtropics and induces southerly moisture fluxes on its downstream flank. These stratospheric PV intrusions and IVT structures are clearly present during the events on 2 November 1994 and 22 January 2005 (Figures 3b and 3c) when extreme precipitation affected larger parts of Egypt and Saudi Arabia and resulted in 600 and 29 fatalities, respectively [De Vries et al., 2013, 2016]. Interestingly, a very similar larger-scale meteorological constellation is observed during the localized heavy rainfall event that affected Jeddah on 25 November 2009 (Figure 3d) and caused 161 deaths, 10,000 people being affected and an estimated damage of about US\$900 million [Deng et al., 2015; De Vries et al., 2016; Yesubabu et al., 2016]. In October 1979, flooding occurred in the eastern parts of Egypt with 50 fatalities and 66,000 people affected [Moawad, 2012; De Vries et al., 2013]. Surprisingly, ERA-Interim did not generate precipitation over Egypt, nevertheless, a vigorous stratospheric PV intrusion and IVT structure are clearly apparent over the region (Figure 3a). The absence of simulated precipitation in ERA-Interim is likely related to poorer information of upper-air observations and satellite data during the early reanalysis period [Dee et al., 2011]. Aphrodite data indicates a local precipitation spot over northwest Saudi Arabia and very low rainfall amounts that extend over eastern Egypt (Figure 3a), which suggests a large underestimation due to the sparse station network in this region. Thus, the algorithm can detect extreme precipitation events based on the larger-scale meteorological features, even when precipitation is underestimated or not represented in the reanalysis and/or observational data sets.

\subsection{Spatial Distribution of PV and IVT Occurrences}

In the next step, we identify the important regions where stratospheric PV intrusions and IVT structures occur during EPDs. Figure 4 presents the spatial distribution of 6-hourly occurrence frequencies of stratospheric PV intrusions and IVT structures during the period of 1979-2015. The calculation of stratospheric PV intrusion occurrences is based on stratospheric PV streamers and cutoffs vertically aggregated over the isentropic surfaces between $310-340 \mathrm{~K}$, with $5 \mathrm{~K}$ intervals. For example, a frequency of $10 \%$ at a particular grid point means that a stratospheric PV streamer or cutoff is present at $10 \%$ of all considered 6-hourly time instances at any of the isentropic surfaces at that specific grid point. A detailed analysis of stratospheric PV intrusions during EPDs on all individual isentropic surfaces demonstrated their importance between 310-340 K (not shown), which is consistent with the selection of isentropic surfaces for year-round extreme precipitation events in the Alpine region by Martius et al. [2006]. This range of isentropic surfaces warrants a seasonally 
independent detection of extreme precipitation events as the isentropic levels where stratospheric PV intrusions typically occur, vary with the seasons.

The spatial distribution of stratospheric PV intrusion occurrences for all 6-hourly time instances reflect the midlatitude baroclinic zone to the north of the Middle East (Figure 4a), where Rossby wave breaking is frequent. Likewise, occurrences of IVT structures reveal the prevalent signature of the Somali jet along the east African coast that transports moisture towards southwest Asia during summer (Figure 4d). For 6-hourly time instances during the $97.5^{\text {th }}$ percentile EPDs, stratospheric PV intrusion and IVT structure frequencies reach their maxima over the eastern Mediterranean $(>54 \%)$ and the southern Red Sea basin (> 60\%), respectively (Figures $4 \mathrm{~b}$ and $4 \mathrm{e}$ ), confirming the importance of midlatitude forcing and poleward moisture transport for extreme precipitation in the Middle East. Figures $4 \mathrm{c}$ and $4 \mathrm{f}$ display the percentage of occurrences of stratospheric PV intrusions and IVT structures during the EPDs relative to all their occurrences. Here, the important areas emerge where stratospheric PV intrusions and IVT structures occur during extreme precipitation events over the region of interest, marked by the blue $\left(25-42^{\circ} \mathrm{E}, 22-32^{\circ} \mathrm{N}\right)$ and $\operatorname{red}\left(30-47^{\circ} \mathrm{E}, 18-28^{\circ} \mathrm{N}\right)$ boxes in Figures $4 \mathrm{c}$ and $4 \mathrm{f}$, respectively, also depicted in Figures $1 \mathrm{~b}$ and 3 . The relatively higher frequencies of IVT structure occurrences as compared to stratospheric PV intrusion occurrences hold some clues of IVT being more important for extreme precipitation than PV.

\subsection{Definitions of PV and IVT Incursions}

To facilitate comparison with EPDs and daily rainfall observations, we formulate the following spatial and temporal criteria for days with stratospheric PV intrusions and IVT structures, hereafter, PV and IVT incursions. Days with PV incursions should have a stratospheric PV streamer or cutoff that overlaps the target area (blue box in Figures 1b, 3 and 4c) for at least 3 of the 4 time instances per day $(00,06,12$ and $18 \mathrm{UTC})$ at one specific level of any isentropic surface between $310-340 \mathrm{~K}$. The rationale behind the requirement of having the stratospheric PV intrusion at one level instead of allowing various levels for different time instances is that isentropic PV is conserved under adiabatic and frictionless conditions and the intention to detect a persistent PV feature. Similarly, days with IVT incursions should have an IVT structure overlapping the target area (red box in Figures 1b, 3 and 4f) for at least 3 of the 4 time instances per day. Note that the northwest-southeast shift between the target areas for the PV and IVT incursions is not a coincidence, but reflects the nature of stratospheric PV intrusions that initiate southerly moisture transport at their downstream flanks, which is consistent with the example cases in Figure 3. Also, we define days with combined PV and IVT incursions when both concur at a particular day. These combined PV and IVT incursions signify tropical-extratropical interactions and enable us to evaluate their climatological importance for precipitation and extreme precipitation in the Middle East.

Importance of PV and IVT Incursions for EPDs

\subsection{Detection EPDs, Precipitation Intensity and Seasonality}

The combined PV and IVT incursions occur on 8.5\% of all days during 1979-2015 and coincide with $89.8 \%(83.2 \%)$ of the $99^{\text {th }}\left(97.5^{\text {th }}\right)$ percentile EPDs (Table 2). PV incursions are relatively common and occur on $41.4 \%$ of all days. In contrast, IVT incursions occur on $11.8 \%$ of all days. Nevertheless, IVT incursions correspond to higher EPD hits $\left(97.8 \%\right.$ and $92.0 \%$ for the $99^{\text {th }}$ and $97.5^{\text {th }}$ percentile EPDs, respectively) as compared to the EPD hits of PV incursions $\left(92.0 \%\right.$ and $90.3 \%$ for the $99^{\text {th }}$ and $97.5^{\text {th }}$ percentile EPDs, respectively). This finding indicates that IVT is a potentially more pertinent predictor for extreme precipitation than PV. A possible explanation is linked to the underlying 
causality of the atmospheric processes that drive extreme precipitation occurrence; stratospheric PV intrusions reach into the subtropics and extract moisture from the tropics that in turn support the heavy rainfall [De Vries et al., 2016], suggesting that IVT is more directly connected to (extreme) precipitation than PV. Indeed, PV and IVT incursions do not occur independently; $72.3 \%$ of IVT incursions are accompanied by PV incursions.

The greater importance of IVT over PV for extreme precipitation also emerges in Figure 5a, which shows the percentage of PV and IVT incursion frequencies for the precipitation intensity distribution ranging from the $13^{\text {th }}$ to the $\geq 99^{\text {th }}$ percentile, with 1 percentile increments. Here, the precipitation distribution is derived from daily ERA-Interim precipitation averaged over the region of interest. IVT incursions occur at $97.8 \%$ of the $\geq 99^{\text {th }}$ precipitation percentile (representing $23.7 \%$ of the total precipitation amounts) and rapidly diminish toward lower percentiles, whereas PV incursion frequencies attain a maximum of $92.6 \%$ at the $98^{\text {th }}-99^{\text {th }}$ precipitation percentile and gradually reduce for lower precipitation intensities. Despite the greater importance of IVT for extreme precipitation than PV, we use the combination of PV and IVT incursions throughout the remainder of the study to reduce the false alarm ratio (Table 2) and to focus on (extreme) precipitation resulting from tropicalextratropical interactions. The combined PV and IVT incursions have somewhat lower frequencies over the entire precipitation intensity distribution than IVT alone, and show a maximum of $89.8 \%$ for the $\geq 99^{\text {th }}$ fraction and then rapidly decrease following the distribution of the precipitation intensity. Importantly, Figure 5a provides clear evidence that both PV and IVT incursions are strongly connected to the precipitation intensity.

Figure $5 \mathrm{~b}$ demonstrates the seasonal distribution of $97.5^{\text {th }}$ percentile EPDs and the frequencies of PV and IVT incursions. EPDs are most frequent in late autumn/early winter (November-January) and early spring (March-April). During the summer months (June-September) the region of interest remains dry, as precipitation generation is suppressed by mid-tropospheric subtropical anticyclones [Zarrin et al., 2010] and middle- and upper-tropospheric large-scale subsidence imposed by the Asian summer monsoon driven circulation [Rodwell and Hoskins, 1996; Ziv et al., 2004; Tyrlis et al., 2013], further strengthened by the regional heat-driven circulation over the Zagros Plateau [Zaitchik et al., 2007]. PV incursions occur frequently from October to May (+/-50\% of the days) and decline substantially from June to September, reflecting the northward retreat of the midlatitude baroclinic zone during summer. Likewise, IVT incursions are observed from October to May and diminish from June to September, when northerly winds dominate the low-level circulation over the Red Sea basin [Tyrlis et al., 2013]. Overall, the combined PV and IVT incursions follow the seasonal distribution of the EPDs, supporting the confidence in the algorithm.

\subsection{Tropospheric Circulation of EPD hits}

Figure 6 shows composites of daily means and normalized anomalies of the tropospheric circulation for EPD hits (i.e. the 282 days of the $97.5^{\text {th }}$ percentile EPDs that coincide with combined PV and IVT incursions). Normalized anomalies were calculated using the 21-day running mean and standard deviation values of daily means over the period of 1979-2015, following De Vries et al. [2016]. These composites provide clear insight into the larger-scale tropospheric circulation associated with the tropical-extratropical interactions that lead to the formation of extreme precipitation. Daily means and normalized anomalies of the 500-hPa geopotential height and sea level pressure demonstrate the intrusion of a midlatitude upper-level trough into the subtropics (<-1.25 STD) and the deepening and northward amplification of the climatological surface trough over the Red Sea region (i.e. the Red Sea Trough) farther downstream (<-0.75 STD), respectively. This picture is consistent both with phase locking of the tropical and midlatitude troughs and with baroclinic wave growth as was observed for 
extreme precipitation events in the region [Rubin et al., 2007; De Vries et al., 2013, 2016]. To the east we notice the features of the climatological subtropical anticyclone over the eastern margins of the Arabian Peninsula (i.e. the Arabian anticyclone). This meteorological configuration induces strong poleward moisture transport over the Red Sea basin (Figure 6a,b), leading to enhanced tropospheric moisture content over the region of interest (Figure 6b). Note that absolute total column water (TCW) amounts are high over the Red Sea basin akin the features of the semi-permanent Red Sea Trough (Figure 6a), whereas anomalous TCW amounts are particularly large over the interior of the Arabian Peninsula (>1.25 STD; Figure 6b). This larger-scale meteorological environment favors sub-synoptic forcing for ascent and the development of (convective) rainstorms and extreme precipitation over the dry desert regions of the Middle East [De Vries et al., 2016]. The tropospheric circulation in Figure 6 corroborates those as observed in case studies and climatological analyses of extreme precipitation events in the region [Evans and Smith, 2006; Kumar et al., 2015; De Vries et al., 2016] as well as those that have direct relevance to the Active Red Sea Trough phenomenon [Kahana et al., 2004; Ziv et al., 2005; Krichak et al., 2012; De Vries et al., 2013] and tropical plumes [Ziv, 2001; Rubin et al., 2007].

\subsection{Missed EPDs and False Alarms}

Since the aim of the algorithm is to detect EPDs, it is of interest to understand why particular EPDs are missed by the algorithm and why, on other days, combined PV and IVT incursions occurred without any resulting extreme precipitation. First of all, it is noteworthy that missed EPDs are not confined to particular months or seasons, but are roughly equally distributed throughout the year (Figure $5 b$ ). The $97.5^{\text {th }}$ percentile EPDs that were missed by the algorithm lacked PV incursions on 33 days and IVT incursions on 27 days. Case-by-case exploration revealed that many EPDs without PV incursions had a broad PV trough over northeast Africa or a stratospheric PV intrusion over the eastern Mediterranean that did not reach into the Middle East. Relaxing the streamer geometrical criteria or expanding the northern boundary of the target area for PV incursions may include some of these missed EPDs, but it would also lead to an excessive increase of false alarms. It is worth noting that broad PV trough structures were also observed by Martius et al. [2006] for extreme precipitation events over the Alpine region that did not coincide with elongated PV streamers. Missed EPDs that lacked IVT incursions exhibited in many cases IVT incursions during one or several days preceding the EPDs, suggesting that sufficient tropospheric moisture amounts were already available over the region of interest. Other missed EPDs that lacked IVT incursions had a relatively large zonal IVT; 10 of the 27 missed EPDs without IVT incursions would be detected when applying a $250 \mathrm{~kg} \mathrm{~m}^{-1} \mathrm{~s}^{-1}$ threshold on the full IVT field. Nevertheless, sensitivity tests demonstrated a substantial deterioration of EPD hits and false alarm ratios when using the full IVT field as compared to the meridional IVT component (not shown), supporting our choice for the latter.

These findings are confirmed by composites of normalized anomalies of TCW, PV at $330 \mathrm{~K}$, and the zonal and meridional IVT components for missed EPDs and false alarms (Figure 7). As a reference, we show composites for EPD hits in Figure 7a, which demonstrate a center of above-normal PV over northeast Africa ( $>1.25$ STD), anomalous northward directed IVT to its east ( $>2$ STD in the meridional IVT), and above-normal TCW over the Arabian Peninsula (>1.25 STD). In the composite for missed EPDs that lacked PV incursions (Figure 7c), we find above-normal PV anomalies over northeast Africa and the eastern Mediterranean with magnitudes of 0.75 STD and 0.5 STD over the respective regions. These PV normalized anomaly patterns thus reflect the signatures of the broad PV trough structures without an elongated form and more northward positioned stratospheric PV intrusions. Regarding missed EPDs that lacked IVT incursions, the composites reveal above-normal TCW anomalies of the same magnitude as for EPD hits (>1.25 STD), though for a more confined 
region (Figure 7d), which corroborates that sufficient tropospheric moisture content was already present over the region of interest at the day of extreme precipitation. This finding is in line with Kumar et al. [2015], who found a build-up of tropospheric moisture content up to 8 days prior to extreme rainfall occurrence over the central part of the Arabian Peninsula. Furthermore, Figure 7d exhibits weak above-normal eastward directed IVT anomalies, reflecting missed EPDs that lacked IVT incursions but had a large zonal IVT.

Days with combined PV and IVT incursions that remained dry $\left(<95^{\text {th }}\right.$ precipitation percentile $)$ are considered as false alarms, which corresponds to a false alarm ratio of $58.3 \%$ (Table 2). False alarm days have at least two different reasons. In reality, these days were not dry, or a physical process or quantity, which is required for precipitation generation, was not considered in the algorithm. Heavy rainfall, especially when occurring locally, may not be adequately represented in ERA-Interim. For example, extreme precipitation and flooding occurred over Egypt and southern Israel in the October months of 1979 (Figure 3a), 1988, 1991, and 1994 [Cools et al., 2012; Moawad, 2012; De Vries et al., 2013]. Daily ERA-Interim precipitation over the region of interest remained below the $95^{\text {th }}$ percentile during these episodes, although combined PV and IVT incursions were detected (not shown). This highlights the capability of the algorithm to recognize the potential for (local) extreme precipitation based on the larger-scale meteorological environment while the precipitation simulation can be of limited quality. Other false alarm days remained indeed dry. Only $9 \%(26 \%)$ of the false alarms days exceeded the $97.5^{\text {th }}\left(95^{\text {th }}\right)$ precipitation percentile in either Aphrodite or TRMM data (over the period of 1998-2007). Composites reveal a key ingredient for extreme precipitation that was missing; high tropospheric moisture content (Figure 7b). TCW normalized anomalies remain relatively low for false alarm days ( $~ 0.5$ STD) as compared to EPDs that were either detected or missed by the algorithm

( 1.25 STD). This finding is in line with Giannakaki and Martius [2016], who found that tropospheric moisture content can be a main factor to distinguish between moderate and extreme precipitation over northern Switzerland. In addition, upper-tropospheric PV anomalies for false alarm days are weaker and centered farther to the northwest (Figure 7b) as compared to EPD hits and missed EPDs (Figure 7a,c,d), suggesting that the PV forcing was insufficient for the formation of (convective) rainstorms and extreme precipitation.

\subsection{Sensitivity of the Algorithm}

Obviously, the performance of the algorithm is sensitive to a number of criteria as specified in sections 2 and 3, including the PV streamer geometry, IVT threshold, the minimum area of the PV and IVT features, and the boundaries of their target areas. We applied the criteria in a manner to maximize the EPD hits and to minimize the false alarms. The most sensitive criteria were found to be the PV streamer length, the IVT threshold, the northern boundary of the target area for PV incursions and the southern boundary of the target area for IVT incursions. Obviously, these two boundaries are strongly related to the extratropical and tropical origin of the stratospheric PV intrusions and IVT structures, respectively, which is also clearly visible in their occurrence frequencies in Figure 4. To illustrate the sensitivity of those parameters, we include EPD hits and false alarm ratios for more restrictive criteria (Table 2), being PV streamer criteria with a length $\mathrm{L}>1000 \mathrm{~km}$ and a ratio of length over width $>1$, and a $250 \mathrm{~kg} \mathrm{~m}^{-1} \mathrm{~s}^{-1}$ threshold on the meridional IVT. The combined PV and IVT incursions occurred on $3.8 \%$ of all days during $1979-2015$ and detected $70.8 \%(59.6 \%)$ of the $99^{\text {th }}$ $\left(97.5^{\text {th }}\right)$ percentile EPDs. The false alarm ratio decreased from $58.3 \%$ to $41.6 \%$, corresponding to a substantial reduction of 673 to 211 false alarm days. Thus, false alarm ratios reduce substantially when applying more restrictive criteria; however, the EPD hits also deteriorate. 
Figure 8a shows the temporal evolution composite of the mean precipitation amounts over the region of interest for the $97.5^{\text {th }}$ percentile EPDs and the corresponding frequencies of 6-hourly stratospheric PV intrusions and IVT structures overlapping their target areas, hereafter 6-hourly PV and IVT incursions. The 6-hourly PV and IVT incursions occur most frequently from -12 UTC to 00 UTC/+06 UTC, confirming their relation to the EPDs. The larger peak in 6-hourly IVT incursion frequencies as compared to 6-hourly PV incursion frequencies confirms again that IVT is a better indicator of extreme precipitation occurrence than PV. Note that the noisy signal in the 6-hourly PV and IVT incursion frequencies stems from diurnal variability, which is also observed for non-extreme precipitation days (not shown). Figure 8a also depicts the characteristics of the 6-hourly PV and IVT incursions, being the averages of the southward extent of the stratospheric PV intrusions and the IVT magnitudes. Interestingly, the average southward extent of 6-hourly PV incursions reaches a minimum in latitude of about $24.5^{\circ} \mathrm{N}$ between -42 UTC and 00 UTC and the average IVT magnitude of 6-hourly IVT incursions attains a maximum of about $420 \mathrm{~kg} \mathrm{~m}^{-1} \mathrm{~s}^{-1}$ between -12 UTC and +24 UTC. This time shift between the minimum of southward reaching PV incursions and peak in IVT magnitude is suggestive of a causal relationship between PV incursions that reach far into the subtropics and initiate the tropical moisture transport into the Middle East, eventually supporting the extreme precipitation events.

We further investigate the relation between the PV and IVT characteristics and the level of extreme precipitation using three categories of precipitation intensities; the $\geq 99^{\text {th }}, 97.5^{\text {th }}-99^{\text {th }}$, and the $95^{\text {th }}$ $97.5^{\text {th }}$ percentiles of daily precipitation in ERA-Interim averaged over the region of interest. Figure $8 \mathrm{~b}$ depicts for each of the three precipitation categories the statistical dispersion and averages of the minimum latitude of stratospheric PV intrusions and IVT magnitudes for time instances having both a 6-hourly PV and IVT incursion. The $\geq 99^{\text {th }}$ precipitation percentile is associated with 6-hourly PV incursions reaching to an average latitude of about $24^{\circ} \mathrm{N}$ and an average IVT magnitude of $439 \mathrm{~kg} \mathrm{~m}^{-1}$ $\mathrm{s}^{-1}$. We find that for the two less severe precipitation categories, on average, the PV incursions reach less far south and the IVT magnitudes reduce, following an almost linear relationship (Figure 8b). In conclusion, the farther south a stratospheric PV intrusion reaches and the higher the IVT magnitude, the more extreme the precipitation.

Another aspect likely to influence the severity of the precipitation is the duration of the PV and IVT incursions. Previous studies have suggested that extreme precipitation events in arid subtropical regions require a persistent disturbance or two successive disturbances [Knippertz, 2007], or, a 'period of incubation' [Kahana et al., 2004; Rubin et al., 2007], to export the moisture from the remote tropics into the subtropics. Likewise, Martius et al. [2006] found that stationarity of PV streamers is linked to the intensity of precipitation over the Alps. We investigate this possible relation through quantifying the average duration of combined PV and IVT incursions preceding the (extreme) precipitation days of the three precipitation categories as specified above, and used for this calculation only the precipitation days that coincide with combined PV and IVT incursions. The combined PV and IVT incursions lasted 1.36 days, 1.03 days, and 0.93 days prior to the (extreme) precipitation day for the $\geq 99^{\text {th }}, 97.5^{\text {th }}-99^{\text {th }}$, and the $95^{\text {th }}-97.5^{\text {th }}$ precipitation percentile categories, respectively. Accordingly, the precipitation extreme is subject to a weak influence of the persistence of the combined PV and IVT incursions; that is, the longer their duration, the more extreme the precipitation.

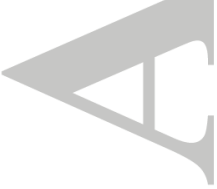




\subsection{Gridded Precipitation Data}

In this section, we quantify the contribution of tropical-extratropical interactions to the climatological precipitation amounts and the extreme precipitation days through calculating their fractions that coincide with combined PV and IVT incursions. To this end we use gridded precipitation data from ERA-Interim, Aphrodite and TRMM. In general, their annual mean precipitation amounts and spatial distribution are in agreement (Figures 9a-c). Note that the periods covered by these data sets differ; however, the focus is primarily on the evaluation of the algorithm rather than intercomparison of the data sets, which has been the subject of other studies [e.g. Tanarhte et al., 2012; El Kenawy and McCabe, 2016]

The combined PV and IVT incursions coincide with more than 50\% of the climatological precipitation amounts over the larger part of the region of interest in all three data sets (Figures 9d-9f). Locally, the fractions of climatological precipitation amounts that are detected by the algorithm exceed $70 \%$ in ERA-Interim and TRMM data, and 60\% in Aphrodite data. Furthermore, we evaluate the fraction of the $99.5^{\text {th }}$ percentile of extreme precipitation days that are detected by the algorithm, which correspond to 69 days, 54 days, and 31 days for the various periods covered by the ERAInterim, Aphrodite and TRMM data sets, respectively. In ERA-Interim, the algorithm captures more than $80 \%$ of the extreme precipitation days over the northwestern parts of Saudi Arabia, and over $60 \%$ in a region that extends from eastern Egypt into the southern margins of Syria and across the larger parts of Iraq (Figure 9g). In Aphrodite and TRMM data, the algorithm detects more than $60 \%$ of the extreme precipitation days over large portions in the region of interest and locally in excess of $70 \%$ up to $80 \%$ (Figures $9 \mathrm{~h}$ and $9 \mathrm{i}$ ).

Relatively low detection rates of the $99.5^{\text {th }}$ percentile of extreme precipitation days over eastern Egypt in Aphrodite data ( $<60 \%)$, and in particular in TRMM data $(<40 \%)$, can be explained by the lack of meaningful extreme precipitation days over this region. The corresponding precipitation amounts are less than $1 \mathrm{~mm} \mathrm{day}^{-1}$, as depicted by the grey contour lines in Figures $9 \mathrm{~h}$ and $9 \mathrm{i}$. Overall, the fractions of detected climatological precipitation amounts and extreme precipitation days are slightly higher in ERA-Interim data than in Aphrodite and TRMM data. Most likely, this stems from the underestimation of localized heavy precipitation in ERA-Interim data, along with heavy rainfall resulting from smaller-scale convective storms being less likely detected by the algorithm than events in which the larger-scale meteorological processes play a more dominant role.

\subsection{Rainfall Records of Stations in Israel and Saudi Arabia}

Finally, we evaluate the performance of the algorithm using daily rainfall records of stations in Israel (1979-2015) and Saudi Arabia (1979-2012). Their spatial distribution over the region of interest is somewhat inhomogeneous and has a relatively low density, but this data source provides highly valuable ground-based rainfall measurements. In general, the annual mean precipitation amounts (Figure 10a) corroborate the rainfall characteristics of the region with a relatively wet climate over northern Israel and southwestern Saudi Arabia, and very dry conditions over the Negev desert and the northwestern and southeastern parts of Saudi Arabia.

Combined PV and IVT incursions contribute to $40-70 \%$ of climatological precipitation amounts at many stations in southern Israel and the northern and western parts of Saudi Arabia (Figure 10d). 
Similarly, the algorithm captures $50-80 \%$ of the heavy precipitation days ( $\geq 20 \mathrm{~mm}^{-1 a y}{ }^{-1}$ ), a commonly adopted climatic index [Zhang et al., 2011], at many stations in this region, with 12 stations exceeding $80 \%$ and two stations reaching a score of $100 \%$ (Figure 10e). These detection rates should be interpreted with some caution as several records, in particular for stations in northwestern Saudi Arabia and southeastern Israel, contain only 1 up to 5 heavy precipitation days over the entire period under consideration (Figure 10b). To obtain a more coherent sample size of the most severe extreme precipitation days, we consider the top 10 extreme precipitation days of each station. The corresponding precipitation thresholds to extract these 10 days range between 8-93 mm day ${ }^{-1}$ and are depicted in Figure 10c. Importantly, the algorithm detects $60-90 \%$ of the top 10 extreme precipitation days at many stations in southern Israel and the northern and western parts of Saudi Arabia.

This analysis underscores the importance of tropical-extratropical interactions for precipitation and extreme precipitation in the arid parts of the Arabian Peninsula and Levant. Beyond this region, the detection rates deteriorate quickly (Figures 10d-10f) due to the restriction of the defined target areas for the PV and IVT incursions as well as the different weather regimes that control the precipitation generation in the extratropics to the north and the tropics to the south. Rainfall along the eastern Mediterranean coast, including northern Israel, stems mostly from Mediterranean cyclones, which are characterized by baroclinic systems that do not necessarily reach far into the subtropics along with westerly moisture transport over the Mediterranean Sea [Saaroni et al., 2010; Ziv et al., 2010]. Precipitation over the elevated topography in southwestern Saudi Arabia is associated with the African monsoon during summer [Almazroui et al., 2012], which explains the anti-correlation between rainfall of several stations in this area and the combined PV and IVT incursions.

\section{$7 \quad$ Conclusions}

Recurrent extreme precipitation events in the arid Middle East can have destructive societal impacts as well as provide essential supplies for fresh water resources. These extreme precipitation events often result from tropical-extratropical interactions, whereby midlatitude forcing and tropical moisture play a key role. In this study, we developed an object-based identification method for extreme precipitation events using stratospheric PV intrusions and structures of high meridional IVT. These two physical processes have previously been postulated as important large-scale precursors for extreme precipitation events, but had thus far not been combined in an algorithm for their identification. PV and IVT features were extracted from ERA-Interim reanalysis data (1979-2015) and the performance of the algorithm was evaluated using various observational precipitation data sets. This approach facilitates an assessment of the importance of tropical-extratropical interactions for precipitation and extreme precipitation in the region that comprises eastern Egypt, southern Israel, Jordan, and the northern and western parts of Saudi Arabia.

Both PV and IVT incursions are intimately linked to extreme precipitation events in the Middle East. Combined PV and IVT incursions (i) detect $90 \%$ of the $99^{\text {th }}$ percentile EPDs and $83 \%$ of the $97.5^{\text {th }}$ percentile EPDs, (ii) are highly associated with the precipitation intensity distribution, and (iii) follow the seasonality of EPDs with dry summer months and peaks in late autumn/early winter and early spring. The severity of the precipitation depends on the PV and IVT characteristics and the persistence of the combined PV and IVT incursions. The farther south a stratospheric PV intrusion reaches, the larger the IVT magnitude, and the longer their combined duration, the more extreme the precipitation. Another important finding is that IVT incursions alone perform nearly as good as the combination of PV and IVT incursions to identify EPDs, indicating a higher potential of IVT as a predictor of extreme precipitation than PV. Application of IVT structures for identification of extreme precipitation in regions elsewhere may require application of the full IVT field instead of only the 
meridional component, and adjustment of the IVT threshold due to spatial variability in background IVT, for example, through adopting percentile-based IVT thresholds as in Guan and Waliser [2015] or anomalous IVT as in Mundhenk et al. [2016a].

The tropospheric circulation during EPD hits (EPDs that coincided with combined PV and IVT incursions) highlights the interaction between the tropical and midlatitude circulations. As a result, tropical moist air masses intrude into the Middle East and support the formation of localized convective storms and widespread rainstorms, which are typical of Active Red Sea Trough events and tropical plumes, respectively. These tropical-extratropical interactions contribute to a substantial fraction of climatological precipitation amounts (40-70\%), and a large number of heavy precipitation days exceeding $20 \mathrm{~mm}^{-1}$ day $^{-1}(50-80 \%)$ and the top 10 extreme precipitation days (60-90\%) in the arid parts of the Levant and the Arabian Peninsula. Thus, tropical-extratropical interactions are not only important for extreme precipitation events that give rise to flood hazards, but also for rainfall that can replenish fresh water resources. The combination of PV and IVT may serve as a concept of synopticscale precursors and ingredients for precipitation and extreme precipitation events. Accordingly, the algorithm may find application for detection of precipitation and extreme precipitation in other dry subtropical regions as well as higher-latitudes where stratospheric PV intrusions and southerly moisture fluxes have been associated with extreme precipitation [e.g. Martius et al., 2006; Froidevaux and Martius, 2016]. Other relevant applications of the algorithm may facilitate an evaluation of the role of PV intrusions in (1) the formation and landfall of atmospheric rivers which have been associated with Rossby wave breaking [Payne and Magnusdottir, 2014; Mundhenk et al., 2016b], and (2) moist air incursions into the Arctic [Liu and Barnes, 2015; Baggett et al., 2016].

Limitations of the algorithm are exemplified through analyzing missed EPDs and false alarms. Missed EPDs are associated with (i) broad PV troughs, (ii) stratospheric PV intrusions that did not reach far into the subtropics, (iii) the prior presence of large tropospheric moisture amounts, and (iv) a large zonal IVT. False alarm days may in reality have experienced localized heavy rainfall that is not represented in the ERA-Interim data, or have remained dry due to insufficient tropospheric moisture amounts. Thus, tropospheric moisture content can explain missed EPDs that lacked IVT incursions (high above-normal TCW anomalies) as well as days with combined PV and IVT incursions that remained dry (low above-normal TCW anomalies). Here, the question arises as to whether the algorithm should be complemented by TCW as a third component or as an alternative to IVT. We refrained from including TCW in the algorithm, as absolute TCW amounts are usually large over the Red Sea region and subject to a strong seasonal cycle, associated with the Red Sea Trough [De Vries et al., 2013]. The use of normalized anomalies of TCW may circumvent these issues; however, this would require statistically-based climatological information of the data set, which is not needed for the current algorithm.

The strength of the algorithm is the identification of local-scale extreme precipitation based on largerscale meteorological features without depending on precipitation data and their inherent limitations. Thus, the algorithm has the potential to serve medium-range weather prediction and early warning systems, and future studies on climatological aspects of extreme precipitation such as their associated teleconnection patterns, interannual variability and trends, and changes due to global warming.

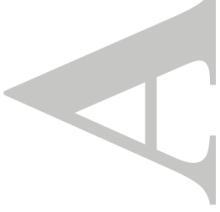




\section{Acknowledgements}

The authors wish to thank CRED, ECMWF, NASA, JAXA, and APHRODITE for providing their data sets, which are available under the following links; EM-DAT (http://www.emdat.be/), ERAInterim (https://www.ecmwf.int/en/research/climate-reanalysis/era-interim), TRMM (https://pmm.nasa.gov/data-access/downloads/trmm), and Aphrodite (http://www.chikyu.ac.jp/precip/english/). We acknowledge the Israeli Atmospheric and Climatic Data Centre (IACDC), supported by the Israeli Ministry of Science, Technology and Space, for providing the Israel Meteorological Service (IMS) daily rainfall records as well as the Ministry of Environment, Water and Agriculture (MEWA) in the Kingdom of Saudi Arabia for providing daily rainfall data. The algorithm is written in the National Center for Atmospheric Research (NCAR) Command Language (NCL) package version 6.3.0, which was also used for the visualization of the data. The algorithm results, as described in section 2.3, are available from the corresponding author upon request. SBF was supported by National Science Foundation grants AGS-1401220 and AGS1723832. The authors wish to thank Michael Sprenger and Heini Wernli for their helpful suggestions for writing the algorithm for PV intrusions. We greatly appreciate the constructive comments of three anonymous reviewers that helped to improve the quality of the manuscript.

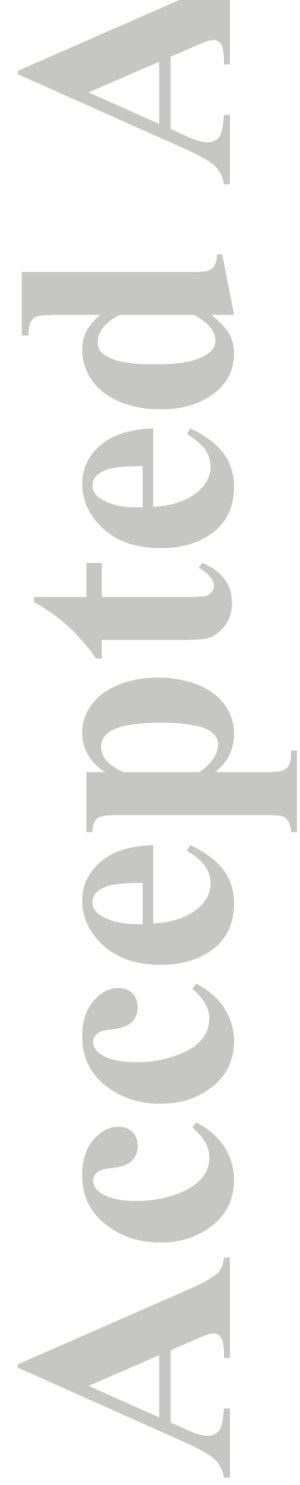




\section{References}

Almazroui, M., M. N. Islam, P. D. Jones, H. Athar, and M. A. Rahman (2012), Recent climate change in the Arabian Peninsula: Seasonal rainfall and temperature climatology of Saudi Arabia for 19792009. Atmos. Res., 111, 29-45.

Almazroui, M., S. Kamil, K. Ammar, K. Keay, and A. O. Alamoudi (2016), Climatology of the 500hPa Mediterranean storms associated with Saudi Arabia wet season precipitation, Clim. Dyn., 48, 3309-3324.

Amin, M. T., S. H. Mahmoud, and A. A. Alazba (2016), Observations, projections and impacts of climate change on water resources in Arabian Peninsula: current and future scenarios, Env. Earth Sci., 75(10), doi:10.1007/s12665-016-5684-4.

Baggett, C., S. Lee, and S. B. Feldstein, 2016: An investigation of the presence of atmospheric rivers over the North Pacific during planetary-scale wave life cycles and their role in Arctic warming. J. Atmos. Sci., 73, 4329-4347, doi:10.1175/JAS-D-16-0033.1.

Barton, Y., P. Giannakaki, H. von Waldow, C. Chevalier, S. Pfahl, and O. Martius (2016), Clustering of regional-scale extreme precipitation events in Southern Switzerland, Mon. Weather Rev., 144, 347 369.

Béguin, A., O. Martius, M. Sprenger, P. Spichtinger, D. Folini, and H. Wernli (2013), Tropopause level Rossby wave breaking in the Northern Hemisphere: A feature-based validation of the ECHAM5-HAM climate model, Int. J. Climatol., 3, 3073-3082.

Cavazos, T., A. C. Comrie, and D. M. Liverman (2002), Intraseasonal variability associated with wet monsoons in southeast Arizona, J. Climate, 15, 2477-2490, doi:10.1175/1520-0442(2002)015,2477: IVAWWM.2.0.CO;2.

Chakraborty, A., S. K. Behera, M. Mujumdar, R. Ohba, and T. Yamagata (2006), Diagnosis of tropospheric moisture over Saudi Arabia and influences of IOD and ENSO, Mon. Weather Rev., 134, 598-617.

Cools, J., P. Vanderkrimpen, G. El Afandi, A. Abdelkhalek, S. Fockedey, M. El Sammany, G. Abdallah, M. El Bihery, W. Bauwens, and M. Huygens (2012), An early warning system for fl an floods in hyper-ärid Egypt, Nat. Haz. Earth Syst. Sci., 12(2), 443-457, doi:10.5194/nhess-12-4432012.

De Vries, A. J., E. Tyrlis, D. Edry, S. O. Krichak, B. Steil, and J. Lelieveld (2013), Extreme precipitation events in the Middle East: Dynamics of the Active Red Sea Trough, J. Geophys. Res., $118,7087-7108$.

De Vries A. J., S. B. Feldstein, M. Riemer, E. Tyrlis, M. Sprenger, M. Baumgart, M. Fnais, and J. Lelieveld (2016), Dynamics of tropical-extratropical interactions and extreme precipitation events in Saudi Arabia in autumn, winter and spring, Q. J. Roy. Meteor. Soc., 142, 1862-1880.

Dee, D. P., et al. (2011), The ERA-Interim reanalysis: Configuration and performance of the data assimilation system, Q. J. R. Meteorol. Soc., 137(656), 553-597, doi:10.1002/qj.828.

Deng, L. P., M. F. McCabe, G. Stenchikov, J. P. Evans, P. A. Kucera (2015), Simulation of flashflood-producing storm events in Saudi Arabia using the Weather Research and Forecasting Model, $J$. Hydrometeor., 16, 615-630. 
Donat, M. G., J. Sillmann, S. Wild, L. V. Alexander, T. Lippmann, and F. W. Zwiers (2014), Consistency of temperature and precipitation extremes across various global gridded in situ and reanalysis datasets, J. Clim., 27(13), 5019-5035.

El Kenawy, A. M., and M. F. McCabe (2016), A multi-decadal assessment of the performance of gauge- and model-based rainfall products over Saudi Arabia: climatology, anomalies and trends, Int. J. Climatol., 36, 656-674.

Evans, J. P., and R. B. Smith (2006), Water vapor transport and the production of precipitation in the eastern fertile crescent, J. Hydrometeorol., 7(6), 1295-1307, doi:10.1175/JHM550.1.

Favors, J. E., and J. T. Abatzoglou (2013), Regional surges of monsoonal moisture into the southwestern United States, Mon. Weather Rev., 141(1), 182-191,doi:10.1175/MWR-D-12-00037.1.

Fröhlich, L., P. Knippertz, A. H. Fink, and E. Hohberger (2013), An objective climatology of tropical plumes, J. Clim., 26(14), 5044-5060.

Froidevaux P., and O. Martius (2016), Exceptional integrated vapour transport toward orography: an important precursor to severe floods in Switzerland, Q. J. Roy. Meteor. Soc., 142, 1997-2012.

Funatsu, B. M., and D. W. Waugh (2008), Connections between potential vorticity intrusions and convection in the Eastern Tropical Pacific, J. Atmos. Sci., 65, 987-1002.

Giannakaki, P., and O. Martius (2016), Synoptic-scale flow structures associated with extreme precipitation events in northern Switzerland, Int. J. Climatol., 36, 2497-2515, doi: 10.1002/joc.4508.

Guan, B., and D. E. Waliser (2015), Detection of atmospheric rivers: Evaluation and application of an algorithm for global studies, J. Geophys. Res. Atmos., 120, 514-12,535, doi:10.1002/2015JD024257.

Hart, N. C. G., C. J. C. Reason, and N. Fauchereau (2010), Tropical-Extratropical Interactions over Southern Africa: Three Cases of Heavy Summer Season Rainfall, Mon. Weather Rev., 138(7), 26082623.

Hart, N. C. G., C. J. C. Reason, and N. Fauchereau (2012), Building a tropical extratropical cloud band metbot, Mon. Weather Rev., 140, 4005-4016.

Hart, N. C. G., C. J. C. Reason, and N. Fauchereau (2013), Cloud bands over southern Africa: Seasonality, contribution to rainfall variability and modulation by the MJO, Clim. Dyn., 41(5-6), 1199-1212, doi:10.1007/s00382-012-1589-4.

Huffman, G. J., R. F. Adler, D. T. Bolvin, G. Gu, E. J. Nelkin, K. P. Bowman, Y. Hong, E. F. Stocker, and D. B. Wolff (2007), The TRMM multisatellite precipitation analysis (TMPA): Quasi-global, multiyear, combined-sensor precipitation estimates at fine scales, J. Hydrometeor., 8, 38-55.

Isotta, F., O. Martius, M. Sprenger, and C. Schwierz (2008), Long-term trends of synoptic-scale breaking

Rossby waves in the Northern Hemisphere between 1958 and 2001, Int. J. Climatol., 28, 1551-1562, doi:10.1002/joc.1647.

Kahana, R., B. Ziv, U. Dayan, and Y. Enzel (2004), Atmospheric predictors for major floods in the Negev desert, Israel, Int. J. Climatol., 24(9), 1137-1147, doi:10.1002/joc.1056.

Knippertz, P. (2003), Tropical-extratropical interactions causing precipitation in northwest Africa: Statistical analysis and seasonal variations, Mon. Weather Rev., 131(12), 3069-3076, doi:10.1175/1520-0493. 
Knippertz, P., A. H. Fink, A. Reiner and P. Speth (2003), Three late summer/early autumn cases of tropical-extratropical interactions causing precipitation in northwest Africa, Mon. Weather Rev., $131(1), 116-135$.

Knippertz, P., and J. E. Martin (2005), Tropical plumes and extreme precipitation in subtropical and tropical West Africa, Q. J. R. Meteorol. Soc., 131(610), 2337-2365.

Knippertz, P. ( 2007), Tropical-extratropical interactions related to upper-troughs at low latitudes, Dyn. Atm. Oceans, 43(1-2), 36-62. doi:10.1016/j.dynatmoce.2006.06.003

Knipperz, P., and H. Wernli (2010), A Lagrangian climatology of tropical moisture exports to the Northern Hemisphere extratropics, J. Clim.,23, 987-1003.

Knippertz, P., H. Wernli H, and G. Glaser (2013), A Global Climatology of Tropical Moisture Exports, J. Climate, 17, 1449-1458.

Krichak, S. O., J. S. Breitgand, and S. B. Feldstein (2012), A conceptual model for the identification of the Active Red Sea Trough Synoptic events over the southeastern Mediterranean, J. App. Meteorol. Climatol., 51(5), 962-971, doi:10.1175/JAMC-D-11-0223.1.

Kumar, K. N., D. Entekhabi, and A. Molini (2015), Hydrological extremes in hyperarid regions: A diagnostic characterization of intense precipitation over the Central Arabian Peninsula, J. Geophys. Res. Atmos., 120, 1637-1650, doi:10.1002/2014JD022341.

Kunz, A., M. Sprenger, and H. Wernli (2015), Climatology of potential vorticity streamers and associated isentropic transport pathways across PV gradient barriers, J. Geophys. Res. Atmos., 120, 3802s. Res

doi:10.1002/2014JD022615.

Lavers, A., G. Villarini (2013a), The nexus between atmospheric rivers and extreme precipitation across Europe, Geophys. Res. Lett., 40, 3259-3264.

Lavers, D. A., and G. Villarini (2013b), Atmospheric rivers and flooding over the Central United States, J. Clim., 26(20), 7829-7836, doi:10.1175/JCLI-D-13-00212.1.

Lavers, D. A., F. Pappenberger, and E. Zsoter (2014), Extending medium-range predictability of extreme hydrological events in Europe, Nat. Commun., 5, 5382, doi:10.1038/ncomms6382.

Liu, C., X. Ren, and X. Yang (2014), Mean flow-storm track relationship and Rossby wave breaking in two types of El-Niño, Adv. Atmos. Sci., 31, 197-210, doi:10.1007/s00376-013-2297-7.

Liu, C., and E. A. Barnes (2015), Extreme moisture transport into the Arctic linked to Rossby wave breaking, J. Geophys. Res. Atmos., 120, 3774-3788, doi:10.1002/2014JD022796.

Madonna, E., S. Limbach, C. Aebi, H. Joos, H. Wernli, and O. Martius (2014a) On the co-occurrence of warm conveyor belt outflows and PV streamers, J. Atmos. Sci., 71, 3668-3673, doi:10.1175/JASD-14-0119.1.

Madonna, E., H. Wernli, H. Joos, and O. Martius (2014b), Warm conveyor belts in the ERA-Interim Dataset (1979-2010). Part I: Climatology and potential vorticity evolution, J. Clim.,27, 3-26, doi: 10.1175/JCLI-D-12-00720.1.

Mahoney, K., D. L. Jackson, P. Neiman, M. Hughes, L. Darby, G. Wick, A. White, E. Sukovich, and C. Cifelli (2016), Understanding the role of atmospheric rivers in heavy precipitation in the southeast 
united states, Mon. Weather Rev., 144(4), 1617-1632.

Martius, O., E. Zenklusen, C. Schwierz, and H. C. Davies (2006), Episodes of Apline heavy precipitation with an overlying elongated stratospheric intrusion: A climatology, Int. J. Climatol., 26, $1149-1164$.

Martius, O., C. Schwierz, and H.C. Davies (2008a), Far-upstream precursors of heavy precipitation events on the Alpine south-side, Q. J. Roy. Meteor. Soc., 134, 417-428.

Martius, O., C. Schwierz, and M. Sprenger (2008b), Dynamical tropopause variability and potential vorticity streamers in the Northern Hemisphere-A climatological analysis, Adv. Atmos. Sci., 25(3), 367-379.

Martius, O., H. Sodemann, H. Joos, S. Pfahl, A. Winschall, M. Croci-Maspoli, M. Graf, E. Madonna, B. Mueller, S. Schemm, J. Sedlacek, M. Sprenger, and H.Wernli (2013), The role of upper-level dynamics and surface processes for the Pakistan flood of July 2010, Q. J. Roy. Meteor. Soc., 139, $1780-1797$.

Massacand, A. C., H. Wernli, and H. C. Davies (1998), Heavy precipitation on the Alpine southside: An upper-level precursor, Geophys. Res. Lett., 25, 1435-1438.

McIntyre, M. E., and T. N. Palmer (1983), Breaking planetary waves in the stratosphere, Nature, 305, 593-600, doi:10.1038/305593a0.

Moawad, M. B. (2012), Predicting and analyzing flash floods of ungauged small-scale drainage basins in the eastern desert of Egypt, J. Geomatics, 6(1), 23-30.

Moore, B. J., K. M. Mahoney, E. M. Sukovich, R. Cifelli, and T. M. Hamill (2015), Climatology and environmental characteristics of extreme precipitation events in the southeastern United States, Mon. Weather Rev., 143, 718-741, doi:10.1175/MWR-D-14-00065.1.

Mundhenk, B. D., E. A. Barnes, and E. D. Maloney (2016a), All-season climatology and variability of atmospheric river frequencies over the North Pacific, J. Clim., 29, 4885-4903.

Mundhenk, B. D., E. A. Barnes, E. D. Maloney, and K. M. Nardi (2016b), Modulation of atmospheric rivers near Alaska and the US West Coast by northeast Pacific height anomalies, J. Geophys. Res. Atmos., 121, 12,751-12,765, doi:10.1002/2016JD025350.

Pascale, S., and S. Bordoni (2016), Tropical and extratropical controls of Gulf of California surges and summertime precipitation over the southwestern United States, Mon. Weather Rev., 144, 26952718, doi:10.1175/MWR-D-15-0429.1.

Payne, A. E., and G. Magnusdottir (2014), Dynamics of landfalling atmospheric rivers over the North Pacific in 30 years of MERRA reanalysis, J. Clim., 27, 7133-7150.

Pfahl, S., and H. Wernli (2012), Quantifying the relevance of cyclones for precipitation extremes, $J$. Clim., 25, 6770-6780, doi:10.1175/JCLI-D-11-00705.1.

Pfahl, S., E, Madonna, M. Boettcher, H. Joos, and H. Wernli (2014), Warm conveyor belts in the ERA-Interim data set (1979 (1979set (19791 Moisture origin and relevance for precipitation, J. Clim., 27, 27.im. origin and relevance for preci

Ralph, F. M., P. J. Nieman, G. A. Wick, S. I. Gutman, M. D. Dettinger, D. R. Cayan, and A. B. White (2006), Flooding on California's Russian River: Role of atmospheric rivers, Geophys. Res. Lett., 33, L13801, doi:10.1029/2006GL026689. 
Rodwell, M. J., and B. J. Hoskins (1996), Monsoon and the dynamics of deserts, Q. J. R. Meteorol. Soc., 122(534), 1385-1404, doi:10.1002/qj.49712253408.

Rutz, J. J., W. J. Steenburgh, and F. M. Ralph (2014), Climatological characteristics of atmospheric rivers and their inland penetration over the western United States, Mon. Weather Rev., 142, 905-921.

Rubin, S., B. Ziv, and N. Paldor (2007), Tropical plumes over eastern North Africa as a source of rain in the Middle East, Mon. Weather Rev., 135(12), 4135-4148.

Saaroni, H., N. Halfon, B. Ziv, P. Alpert, and H. Kutiel (2010), Links between the rainfall regime in Israel and location and intensity of Cyprus Lows, Int. J. Climatol., 30, 1014-1025,

doi:10.1002/joc.1912.

Schlemmer, L., O. Martius, M. Sprenger, C. Schwierz, and A. Twitchett (2010), Disentangling the forcing mechanisms of a heavy precipitation event along the alpine south side using potential vorticity inversion, Mon. Weather Rev., 138, 2336-2353, doi:10.1175/2009MWR3202.1.

Schulz, S., G. H. de Rooij, N. Michelsen, R. Rausch, C. Siebert,C. Schüth, M. Al- Saud, and R. Merz (2016), Estimating groundwater recharge for an arid karst system using a combined approach of timelapse camera monitoring and water balance modelling, Hydrol. Process., 30, 771-782.

Škerlak, B., M. Sprenger, S. Pfahl, E. Tyrlis, and H. Wernli (2015), Tropopause folds in ERAInterim:

Global climatology and relation to extreme weather events, J. Geophys. Res. Atmos., 120, 4860-4877, doi:10.1002/2014JD022787.

Sprenger, M., H.Wernli, and M. Bourqui (2007), Stratosphere-troposphere exchange and its relation to potential vorticity streamers and cutoffs near the extratropical tropopause, J. Atmos. Sci., 64, 15871602.

Sprenger, M., O. Martius, and J. Arnold (2013), Cold surge episodes over southeastern Brazil - a potential vorticity perspective, Int. J. Climatol., 33, 2758-2767.

Strong, C., and G. Magnusdottir (2008), Tropospheric Rossby wave breaking and the NAO/NAM, $J$. Atmos. Sci., 65(9), 2861-2876, doi:10.1175/2008JAS2632.1.

Swales, D., M. Alexander, and M. Hughes (2016), Examining moisture pathways and extreme precipitation in the U.S. Intermountain West using self-organizing maps, Geophys. Res. Lett., 43, 1727-1735, doi:10.1002/2015GL067478.

Tanarhte, M., P. Hadjinicolaou, and J. Lelieveld (2012), Intercomparison of temperature and precipitation data sets based on observations in the Mediterranean and the Middle East. J. Geophys. Res. Atm., 47, 2361-2371. 117:D12102. doi:10.1029/2011JD017293.

Tyrlis, E., J. Lelieveld, and B. Steil (2013), The summer circulation over the eastern Mediterranean and the Middle East: influence of the South Asian monsoon, Clim.Dyn., 40(5-6), 1103-1123, doi:10.1007/s00382-012-1528-4.

Vellore, R., M. Kaplan, R. Krishnan, J. Lewis, S. Sabade, N. Deshpande, B. Singh, R. Madhura, and M. V. S. Rama Rao (2016), Monsoon-extratropical circulation interactions in Himalayan extreme rainfall, Clim. Dyn., 46: 3517-3546.

Waliser, D., and B. Guan (2017), Extreme winds and precipitation during landfall of atmospheric rivers, Nature, $10(3), 179-183$ 
Wernli, H., and M. Sprenger (2007), Identification and ERA-15 Climatology of Potential Vorticity Streamers and Cutoffs near the Extratropical Tropopause, J. Atm. Sci., 64, 1569-1586.

Wright, W. J. (1997), Tropical-extratropical cloudbands and Australian rainfall: 1. Climatalogy, Int. J. Climatol., 17(8), 807-829.

Yatagai, A., K. Kamiguchi, O. Arakawa, A. Hamada, N. Yasutomi, and A. Kitoh (2012), Aphrodite constructing a long-term daily gridded precipitation dataset for Asia based on a dense network of rain gauges, Bull. Am. Meteorol. Soc., 93(9), 1401-1415, doi:10.1175/BAMS-D-11-00122.1.

Yesubabu, V., C. V. Srinivas, S. Langodan, and I. Hoteit (2016), Predicting extreme rainfall events over Jeddah, Saudi Arabia: impact of data assimilation with conventional and satellite observations, Q. J. Roy. Meteor. Soc., 142, 327-348.

Zaitchik, B. J., J. P. Evans, and R. B. Smith (2007), Regional impact of an elevated heat source: the Zagros plateau of Iran, J. Clim., 20(16), 4133-4146, doi:10.1175/JCLI4248.1.

Zarrin, A., H. Ghaemi, M. Azadi, and M. Farajzadeh (2010), The spatial pattern of summertime subtropical anticyclones over Asia and Africa: A climatological review, Int. J. Climatol., 30, 159-173, doi:10.1002/joc.1879.

Zhang, X., L. Alexander, G. C. Hegerl, P. Jones, A. Klein Tank, T. C. Peterson, B. Trewin, and F. W. Zwiers (2011), Indices for monitoring changes in extremes based on daily temperature and precipitation data, Clim. Change, 2, 851-870. doi: 10.1002/xcc.147.

Ziv, B. (2001), A subtropical rainstorm associated with a tropical plume over Africa and the MiddleEast, Theor. Appl. Climatol., 68(1-2), 91-102.

Ziv, B., H. Saaroni, and P. Alpert (2004), The factors governing the summer regime of the eastern Mediterranean, Int. J. Climatol., 24(14), 1859-1871, doi:10.1002/joc.1113.

Ziv, B., U. Dayan, and D. Sharon (2005), A mid-winter, tropical extreme flood-producing storm in southern Israel: Synoptic scale analysis, Meteorol. Atm. Phys., 88(1-2), 53-63.

Ziv, B., H. Saaroni, M. Romem, E. Heifetz, N. Harnik, A. Baharad (2010), Analysis of conveyor belts in winter Mediterranean cyclones, Theor. Appl. Climatol., 99, 441-455. 
Table 1: Sensitivity of PV Streamer Geometry and Thresholds (1979-2015)

\begin{tabular}{|c|c|c|c|c|}
\hline & all days & $\begin{array}{c}\text { EPD hits } \\
\geq 99^{\text {th }} \text { percentile }\end{array}$ & $\begin{array}{l}\text { EPD hits } \\
\geq 97.5^{\text {th }} \\
\text { percentile } \\
\end{array}$ & $\begin{array}{c}\text { false alarm ratio } \\
<95^{\text {th }} \text { percentile } \\
\text { precipitation }\end{array}$ \\
\hline \multicolumn{5}{|c|}{ PV streamer geometry previous studies } \\
\hline $\begin{array}{c}\mathrm{W}<800, \mathrm{LC}>1500 \mathrm{~km} \\
{[\text { Wernli and Sprenger, }} \\
\text { 2007] }\end{array}$ & $37.9 \%$ & $88.3 \%$ & $83.5 \%$ & $89.4 \%$ \\
\hline $\begin{array}{c}\mathrm{W}<1500, \mathrm{LC}>2000 \mathrm{~km}, \mathrm{r}>2 \\
{[\text { Sprenger et al., 2013] }}\end{array}$ & $42.4 \%$ & $93.4 \%$ & $90.0 \%$ & $89.8 \%$ \\
\hline $\mathrm{W}<1500, \mathrm{LC}>3000 \mathrm{~km}, \mathrm{r}>3$ & $34.3 \%$ & $87.6 \%$ & $79.4 \%$ & $89.0 \%$ \\
\hline \multicolumn{5}{|c|}{ New PV streamer geometry } \\
\hline $\begin{array}{c}\mathrm{W}<1500, \mathrm{~L}>650 \mathrm{~km}, \\
\mathrm{r}>0.65\end{array}$ & $41.4 \%$ & $92.0 \%$ & $90.3 \%$ & $89.6 \%$ \\
\hline $\mathrm{W}<1500, \mathrm{~L}>800 \mathrm{~km}, \mathrm{r}>0.8$ & $37.8 \%$ & $91.2 \%$ & $86.1 \%$ & $89.2 \%$ \\
\hline $\mathrm{W}<1500, \mathrm{~L}>1000 \mathrm{~km}, \mathrm{r}>1$ & $34.1 \%$ & $86.1 \%$ & $80.5 \%$ & $88.8 \%$ \\
\hline
\end{tabular}

In bold the streamer criteria used in this study unless mentioned otherwise 
Table 2: Performance Algorithm (1979-2015)

\begin{tabular}{|c|c|c|c|c|}
\hline & all days & $\begin{array}{c}\text { EPD hits } \\
\geq 99^{\text {th }} \text { percentile }\end{array}$ & $\begin{array}{c}\text { EPD hits } \\
\geq 97.5^{\text {th }} \text { percentile }\end{array}$ & $\begin{array}{c}\text { false alarm ratio } \\
<95^{\text {th }} \text { percentile } \\
\text { precipitation }\end{array}$ \\
\hline \multicolumn{5}{|c|}{$\begin{array}{l}\text { generous criteria } \\
\text { PV (W<1500 km, } \mathbf{L}>\mathbf{6 5 0} \mathbf{~ k m , ~} \mathbf{r}>\mathbf{0 . 6 5}) \& \text { meridional IVT }\left(\mathbf{2 0 0} \mathbf{~ k g ~ m}^{-\mathbf{1}} \mathbf{s}^{-\mathbf{1}}\right)\end{array}$} \\
\hline PV & $41.4 \%$ & $92.0 \%$ & $90.3 \%$ & $89.6 \%$ \\
\hline IVT & $11.8 \%$ & $97.8 \%$ & $92.0 \%$ & $65.6 \%$ \\
\hline PV \& IVT & $8.5 \%$ & $89.8 \%$ & $83.2 \%$ & $58.3 \%$ \\
\hline \multicolumn{5}{|c|}{$\begin{array}{c}\text { restrictive criteria } \\
\text { PV }(\mathrm{W}<1500 \mathrm{~km}, \mathbf{L}>\mathbf{1 0 0 0} \mathbf{~ k m}, \mathbf{r}>\mathbf{1}) \& \text { meridional IVT }\left(\mathbf{2 5 0} \mathbf{~ k g ~ m}^{-\mathbf{1}} \mathbf{s}^{-\mathbf{1}}\right) \\
\end{array}$} \\
\hline $\mathrm{PV}$ & $34.1 \%$ & $86.1 \%$ & $80.5 \%$ & $88.8 \%$ \\
\hline IVT & $5.3 \%$ & $81.8 \%$ & $70.2 \%$ & $49.0 \%$ \\
\hline PV \& IVT & $3.8 \%$ & $70.8 \%$ & $59.6 \%$ & $41.6 \%$ \\
\hline
\end{tabular}

In bold the different settings of the generous and restrictive criteria

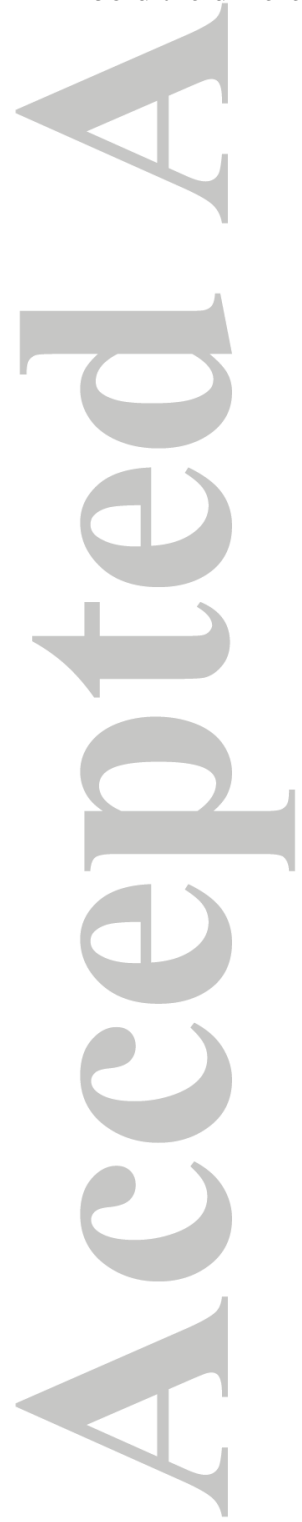




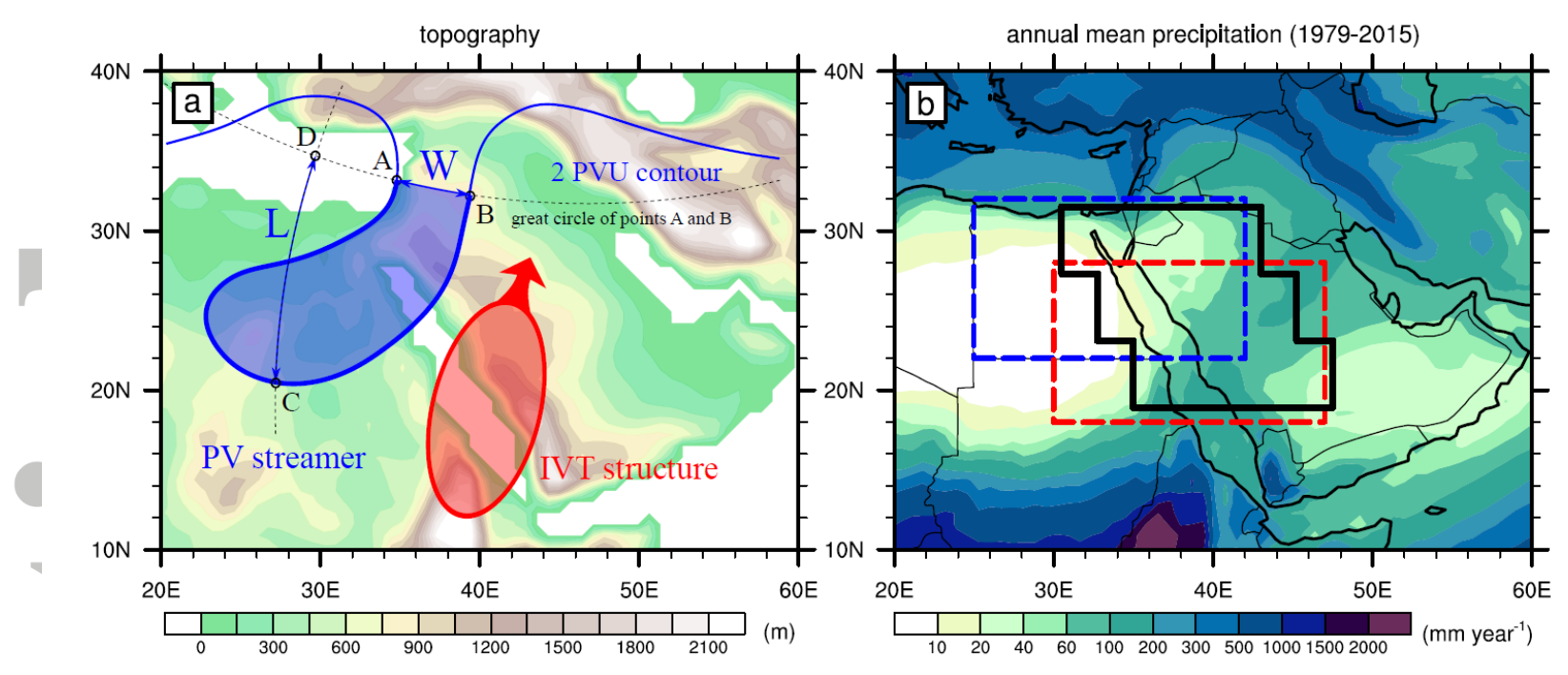

Figure 1. The Middle East region with (a) the topography from ERA-Interim data and a schematic representation of tropical-extratropical interactions, involving the intrusion of a midlatitude upperlevel trough and an incursion of tropical moisture into the region, and (b) the annual mean precipitation $\left(\mathrm{mm} \mathrm{year}^{-1}\right)$ in ERA-Interim data (1979-2015). In (a), the potential vorticity streamer geometrical criteria are depicted, being the width (W) and length (L) for the pair of contour points A and B on a 2 PVU contour at an isentropic surface; see the text in section 2.3 for details. In (b) the box for defining the extreme precipitation days is illustrated by black lines encompassing three imaginary boxes from north to south; box $1\left(27.3-31.5^{\circ} \mathrm{N}, 30.5-43.0^{\circ} \mathrm{E}\right)$, box $2\left(23.1-27.3^{\circ} \mathrm{N}, 32.75-45.25^{\circ} \mathrm{E}\right)$, and box $3\left(18.9-23.1^{\circ} \mathrm{N}\right.$ and $\left.35.0-47.5^{\circ} \mathrm{E}\right)$, see section 2.2. In (b) also the target areas for defining PV (blue box; $22-32^{\circ} \mathrm{N}, 25-42^{\circ} \mathrm{E}$ ) and IVT (red box; $18-28^{\circ} \mathrm{N}, 30-47^{\circ} \mathrm{E}$ ) incursions, see section 3.3.

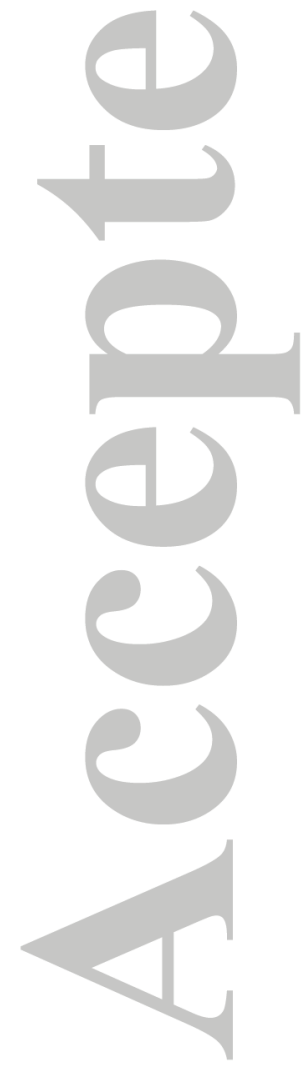


a

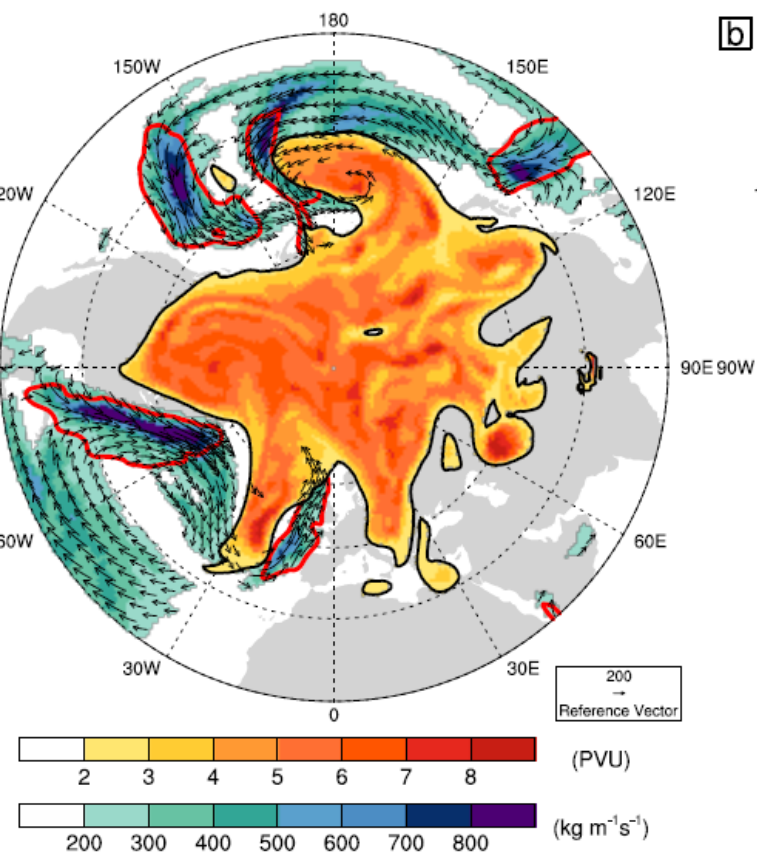

b

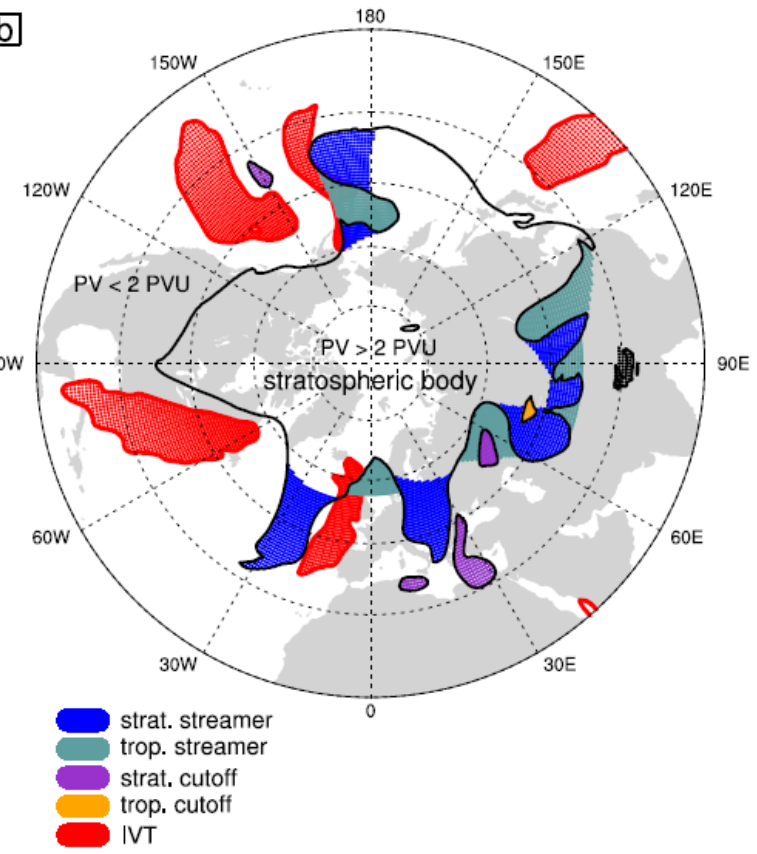

Figure 2. An example of the algorithm results on 14 January 2005, 12 UTC, showing in (a) the PV $(\mathrm{PVU})$ at $315 \mathrm{~K}$, the magnitude and vectors of the full IVT $\left(\mathrm{kg} \mathrm{m}^{-1} \mathrm{~s}^{-1}\right)$, the 2 PVU contours (black lines) and the $200 \mathrm{~kg} \mathrm{~m}^{-1} \mathrm{~s}^{-1}$ meridional IVT contours (red lines), and in (b) the identified stratospheric and tropospheric PV streamers and cutoffs, and IVT structures, as indicated in the legend. 

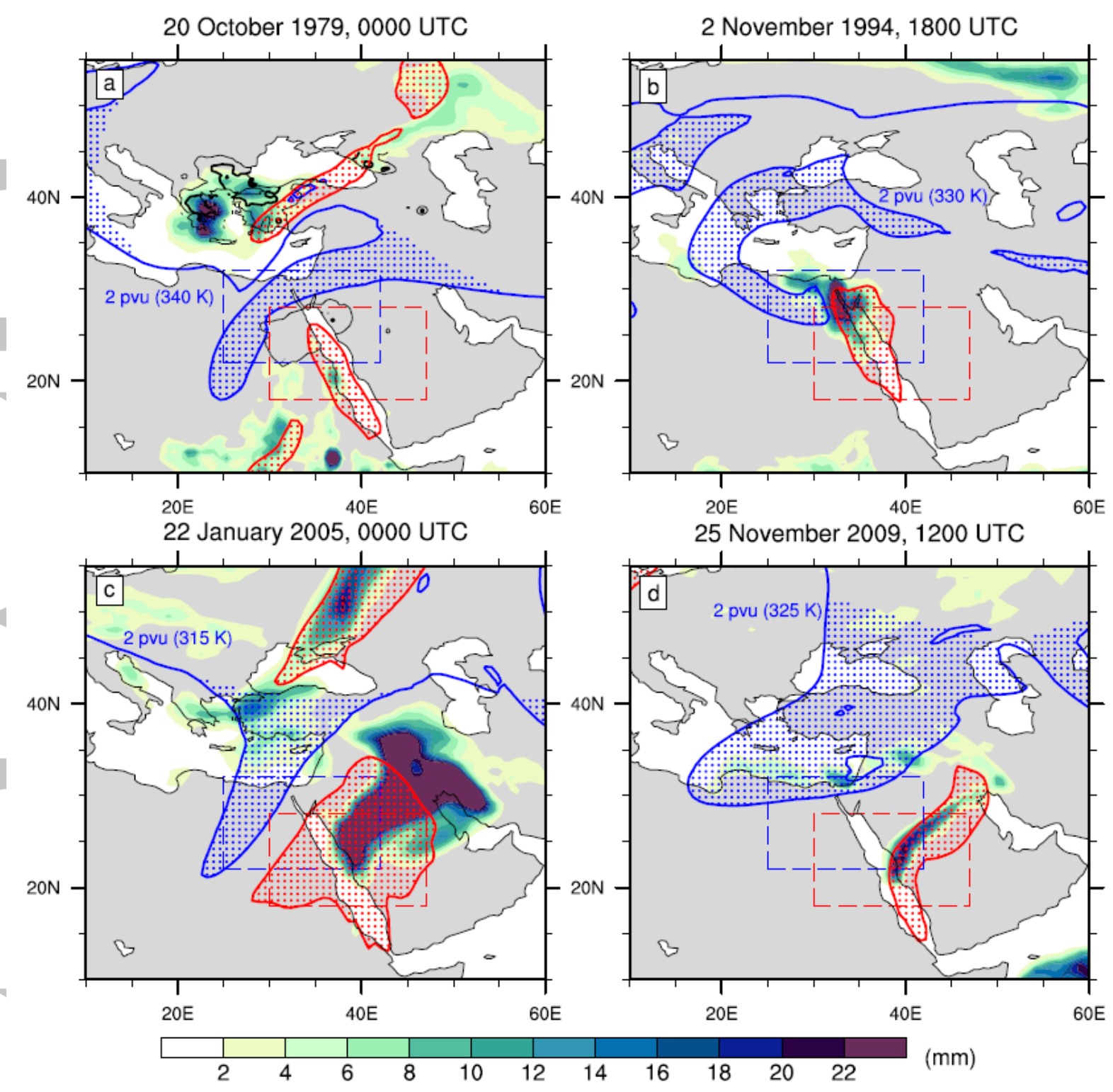

Figure 3. Daily precipitation $(\mathrm{mm})$ from ERA-Interim data (colors), 2 PVU contours at indicated isentropic surfaces (blue lines) and $200 \mathrm{~kg} \mathrm{~m}^{-1} \mathrm{~s}^{-1}$ meridional IVT contours (red lines), and the grid points of stratospheric PV streamers and cutoffs (blue dots) and IVT structures (red dots) for 4 example cases; (a) 20 October 1979, 00 UTC, (b) 2 November 1994, 18 UTC, (c) 22 January 2005, 00 UTC, and (d) 25 November 2009, 12 UTC. In (a) also the daily precipitation from Aphrodite data in black contours at $2 \mathrm{~mm}$ day $^{-1}$ (thin lines) and $10 \mathrm{~mm} \mathrm{day}^{-1}$ (tick lines). The dashed blue and red boxes in (a)-(d) bound the target areas for defining PV and IVT incursions, as in Figure 1b, see the text in section 3.3. 

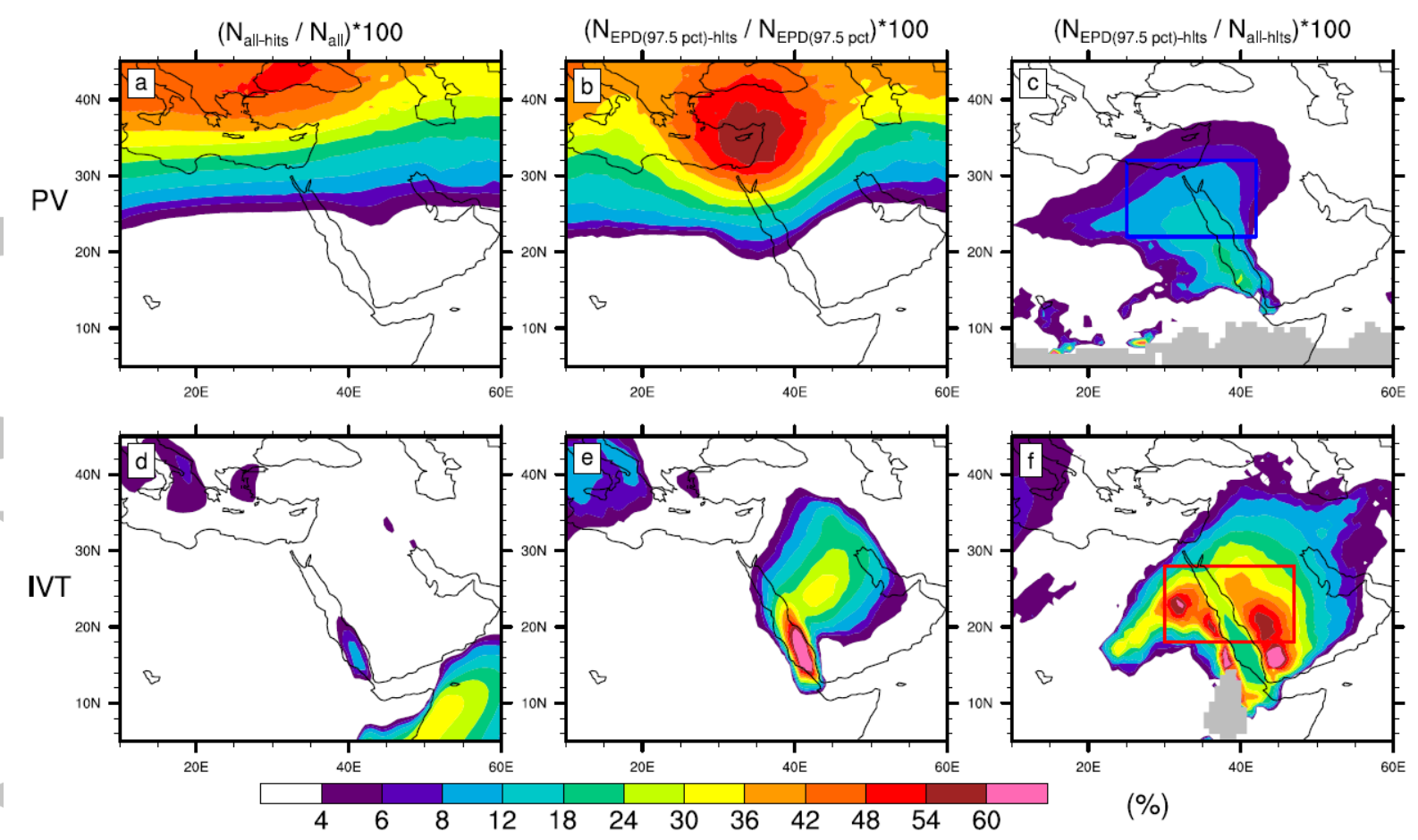

Figure 4. The climatology of 6-hourly occurrence frequencies (\%) of (top) aggregated stratospheric PV streamers and cutoffs, and (bottom) IVT structures during the period 1979-2015. The panels show $(a, d)$ their frequencies for all time instances, $(b, e)$ their frequencies for the time instances during the $97,5^{\text {th }}$ percentile EPDs, and (c,f) the frequencies of their occurrences during the $97,5^{\text {th }}$ percentile EPDs relative to their occurrences during all time instances. The vertically aggregated fields in panels $(a, b)$ are obtained through translating for each 6-hourly time instance the 3-dimensional binary field to 2dimensional binary field with a 'one' if any isentropic surface between 310-340 K with $5 \mathrm{~K}$ intervals has a stratospheric PV streamer or cutoff and a 'zero' otherwise. Grey shading in (c,f) indicate areas where the PV and IVT have zero occurrences during all time instances. The blue and red boxes in (c) and (f) mark the target areas for defining PV and IVT incursions, respectively, as in Figures $1 \mathrm{~b}$ and 3. 


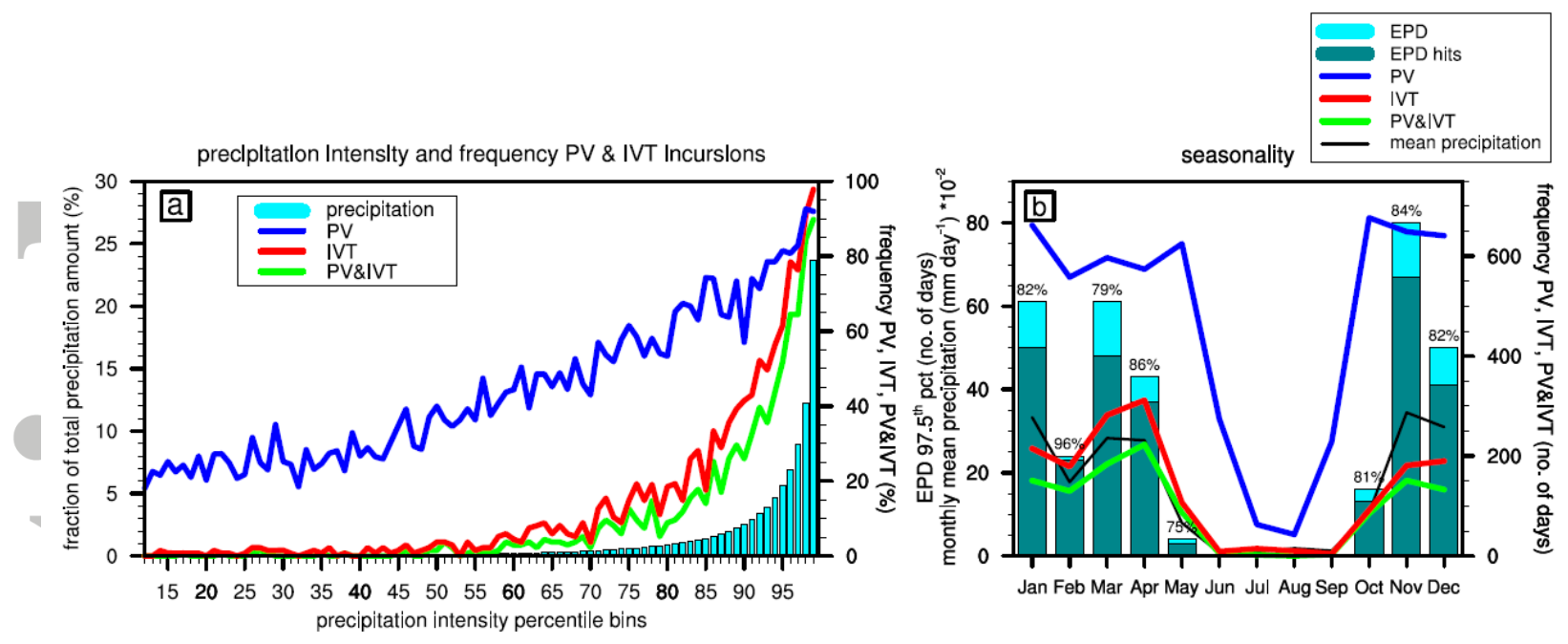

Figure 5. (a) Precipitation intensity bins from the $13^{\text {th }}$ to the $99^{\text {th }}$ percentile with 1 percentile increments, the corresponding fractions of the total precipitation amount over the region of interest (blue bars), and the corresponding frequencies (\%) of coinciding PV incursions (blue lines), IVT incursions (red lines), and combined PV and IVT incursions (green lines). In (b) the monthly distribution of all $97.5^{\text {th }}$ percentile EPDs (light blue color bars), the EPDs detected by the combined PV and IVT incursions (green color bars) and the number of PV incursions (blue lines), IVT incursions (red lines), combined PV and IVT incursions (green lines), and the mean precipitation amounts (black thin lines). The fractions of EPDs that coincide with combined PV and IVT incursions relative to all EPDs (\%) are indicated by the numbers above the color bars. 


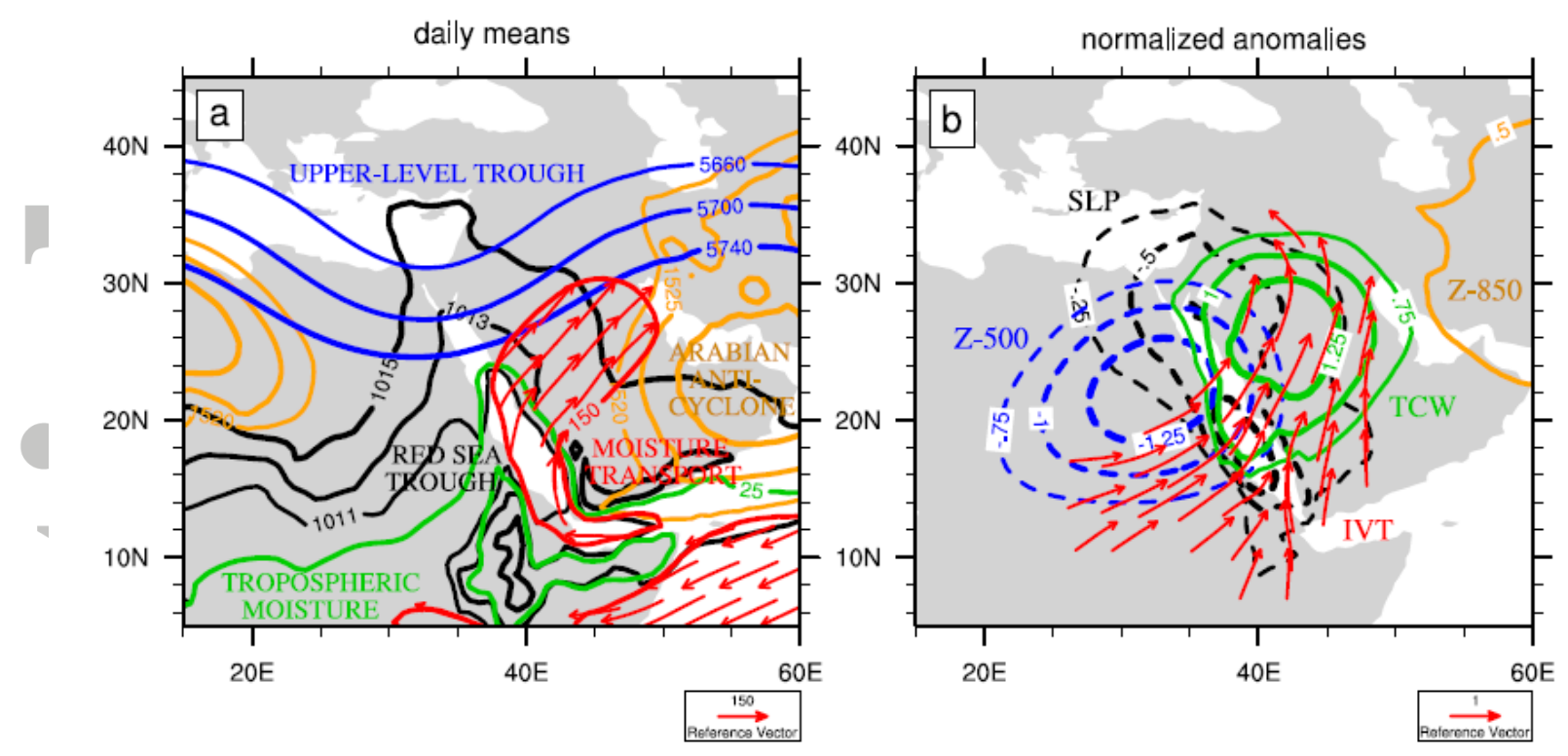

Figure 6. Composites of (a) daily means and (b) normalized anomalies for $97.5^{\text {th }}$ percentile EPD hits (282 days), see the text for details. In (a) the sea level pressure (hPa; black contours), geopotential height (gpm) at $500 \mathrm{hPa}$ (blue contours) and at $850 \mathrm{hPa}$ (orange contours), total column water (green contour at $25 \mathrm{~kg} \mathrm{~m}^{-2}$ ), and the IVT magnitude (red contour at $150 \mathrm{~kg} \mathrm{~m}^{-1} \mathrm{~s}^{-1}$ ) and IVT direction where their magnitude exceeds $150 \mathrm{~kg} \mathrm{~m}^{-1} \mathrm{~s}^{-1}$ (red vectors). In (b) their normalized anomalies (STD) as in (a) without the IVT magnitude and with the IVT vectors composed of their zonal and meridional components and only displayed where their vector length exceeds 1 STD. 

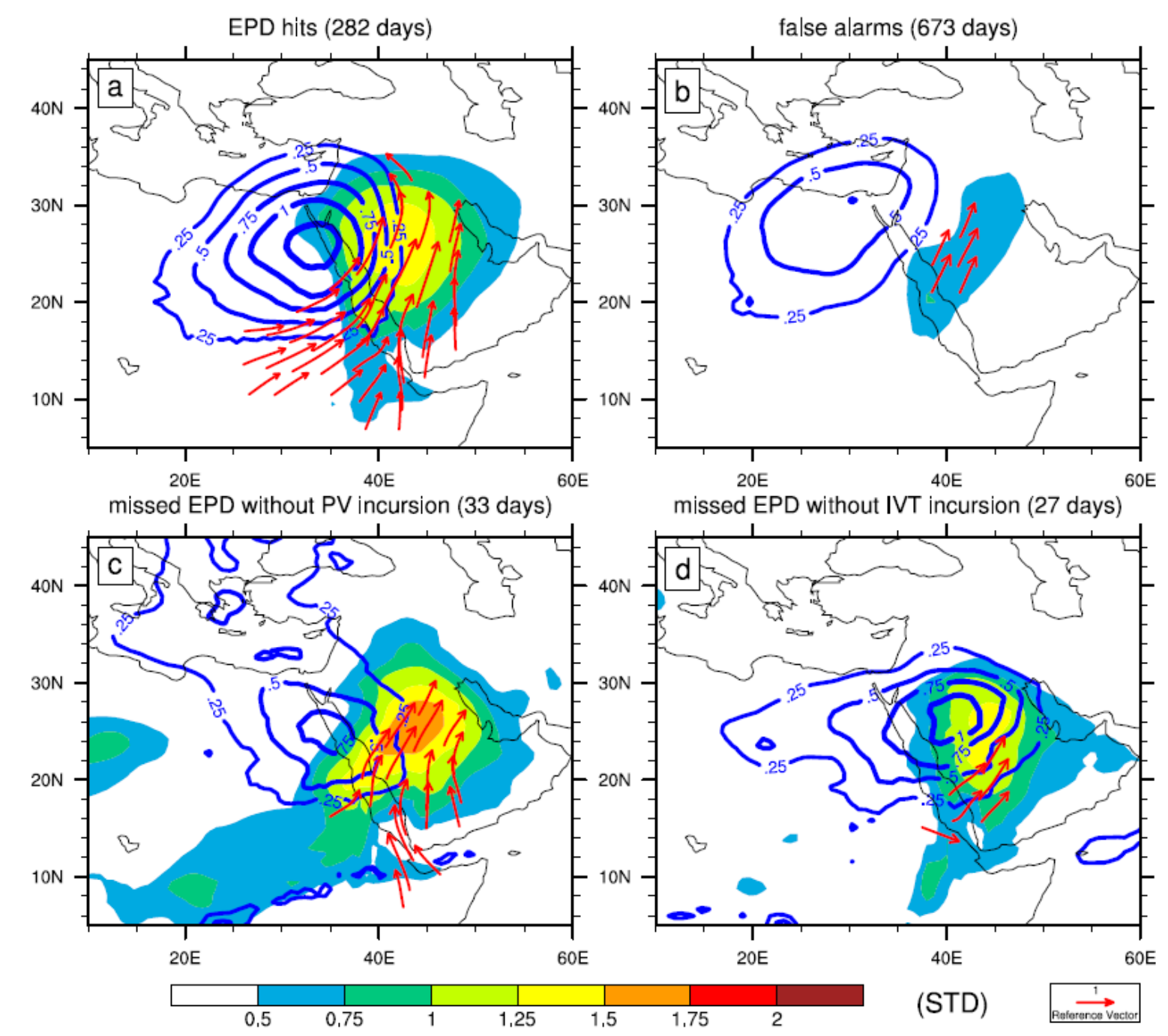

Figure 7. Composites of normalized anomalies (STD) of TCW (colors), PV at $330 \mathrm{~K}$ (blue contour lines), and the IVT vectors (red) composed of their zonal and meridional components and only displayed where their vector length exceeds 1 STD for (a) EPD hits, (b) false alarms, (c) missed EPDs without PV incursion, and (d) missed EPDs without IVT incursion. The EPDs correspond to the $\geq 97.5^{\text {th }}$ percentile, while the false alarms are defined as days with combined PV and IVT incursions and $<95^{\text {th }}$ percentile of daily precipitation in ERA-Interim averaged over the grid points in the region of interest. 

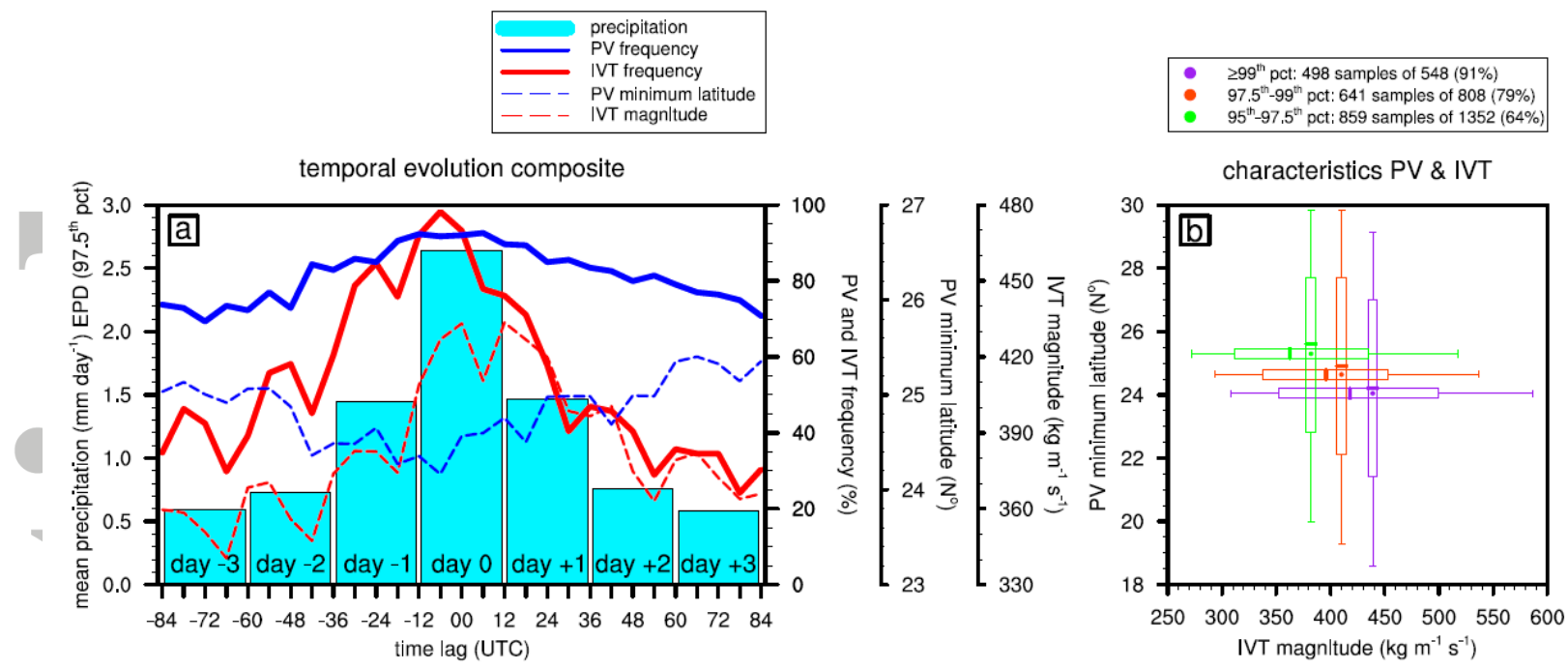

Figure 8. (a) Composites of the temporal evolution of the daily mean precipitation amounts, averaged over the grid points in the region of interest, indicated by the black box in Figure $1 \mathrm{~b}$, for the $97.5^{\text {th }}$ percentile EPDs (blue color bars), and the corresponding 6-hourly frequencies of PV (blue lines) and IVT (red lines) incursions. Average minimum latitudes $\left({ }^{\circ} \mathrm{N}\right)$ and IVT magnitudes $\left(\mathrm{kg} \mathrm{m}^{-1} \mathrm{~s}^{-1}\right)$ of these 6-hourly PV and IVT incursions are denoted by the dashed blue and red lines, respectively. In (b) the statistical dispersion (boxes and whiskers) and averages (dots) of the characteristics of 6-hourly PV and IVT incursions for three precipitation intensity categories with the $\geq 99^{\text {th }}$ (purple), $97.5^{\text {th }}-99^{\text {th }}$ (orange), and $95^{\text {th }}-97.5^{\text {th }}$ (green) precipitation percentiles. The vertically (horizontally) oriented boxes and whiskers display the spread of the PV minimum latitude (IVT magnitude) and are positioned on the average IVT magnitude (PV minimum latitude) of the corresponding precipitation intensity category. The boxes denote the lower and upper quartiles, the whiskers the lower and upper deciles, and the thick lines within the boxes the medians. For the calculation of the spread and average characteristics, we only used the 6-hourly time instances that have both a PV and IVT incursion. The numbers of these time instances (samples) and their percentage relative to all available time instances of the precipitation intensity categories are indicated in the legend. When 6-hourly time instances have multiple stratospheric PV intrusions in the target area and/or at multiple isentropic surfaces, we use the stratospheric PV intrusion with the lowest latitude. Likewise, when 6-hourly time instances have multiple IVT structures in the target area, we use the IVT structure with the largest IVT magnitude. 

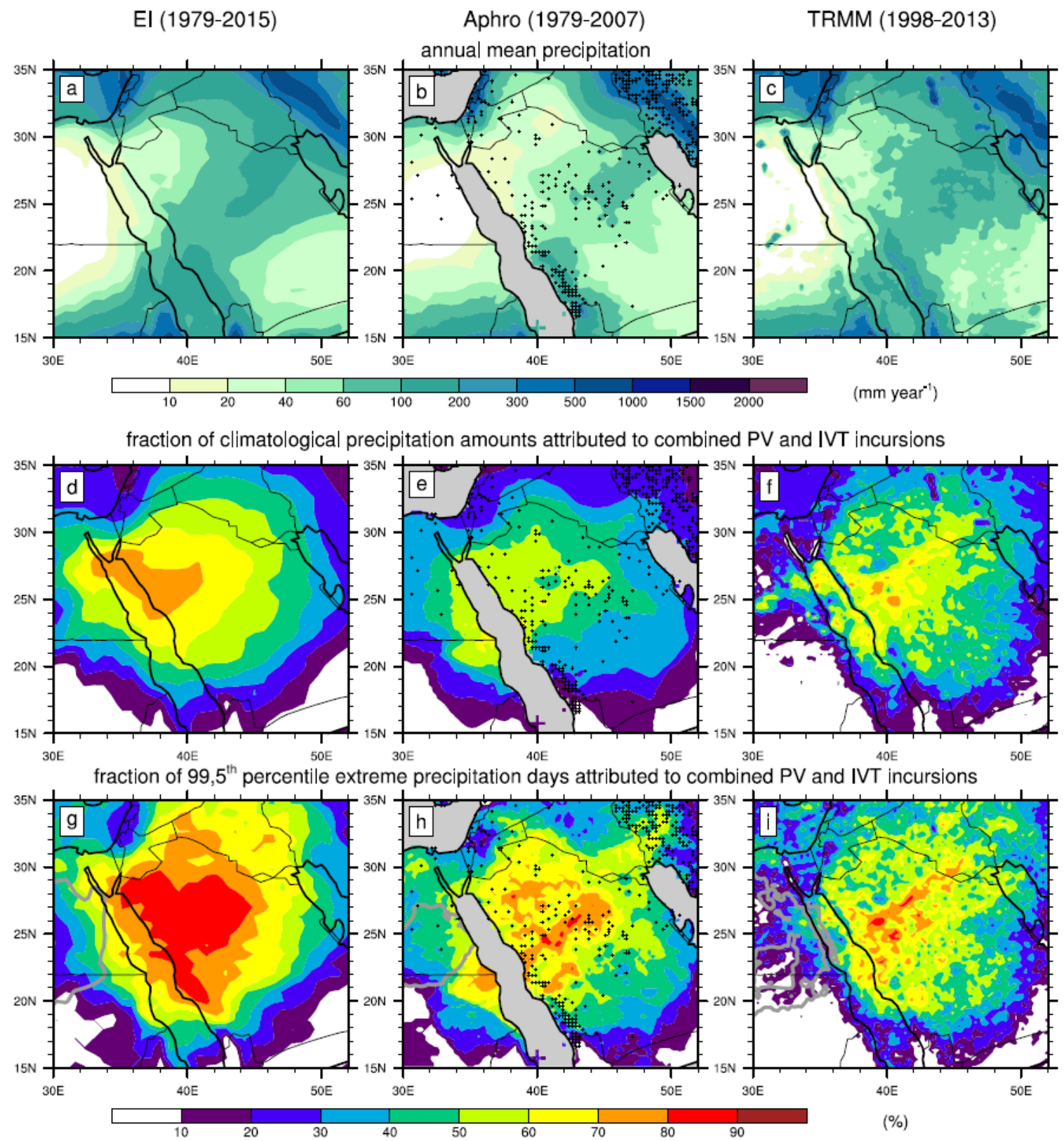

Figure 9. The spatial distribution of the (a-c) annual mean precipitation amounts (mm year ${ }^{-1}$ ), and the fractions of (d-f) the climatological precipitation amounts and (g-i) the $99.5^{\text {th }}$ percentile extreme precipitation days that coincide with combined PV and IVT incursions in (left) ERA-Interim (19792015), (middle) Aphrodite (1979-2007), and (right) TRMM (1998-2013). The markers in (b,e,h) display the grid boxes that are represented by at least 1 station in Aphrodite data for $>50 \%$ of the days, and the grey shading masks areas with missing values for $>50 \%$ of the days. The grey contour lines in $(\mathrm{g}-\mathrm{i})$ denote a precipitation threshold of $1 \mathrm{~mm}^{\mathrm{m}} \mathrm{day}^{-1}$ that corresponds to the $99.5^{\text {th }}$ precipitation percentile. 

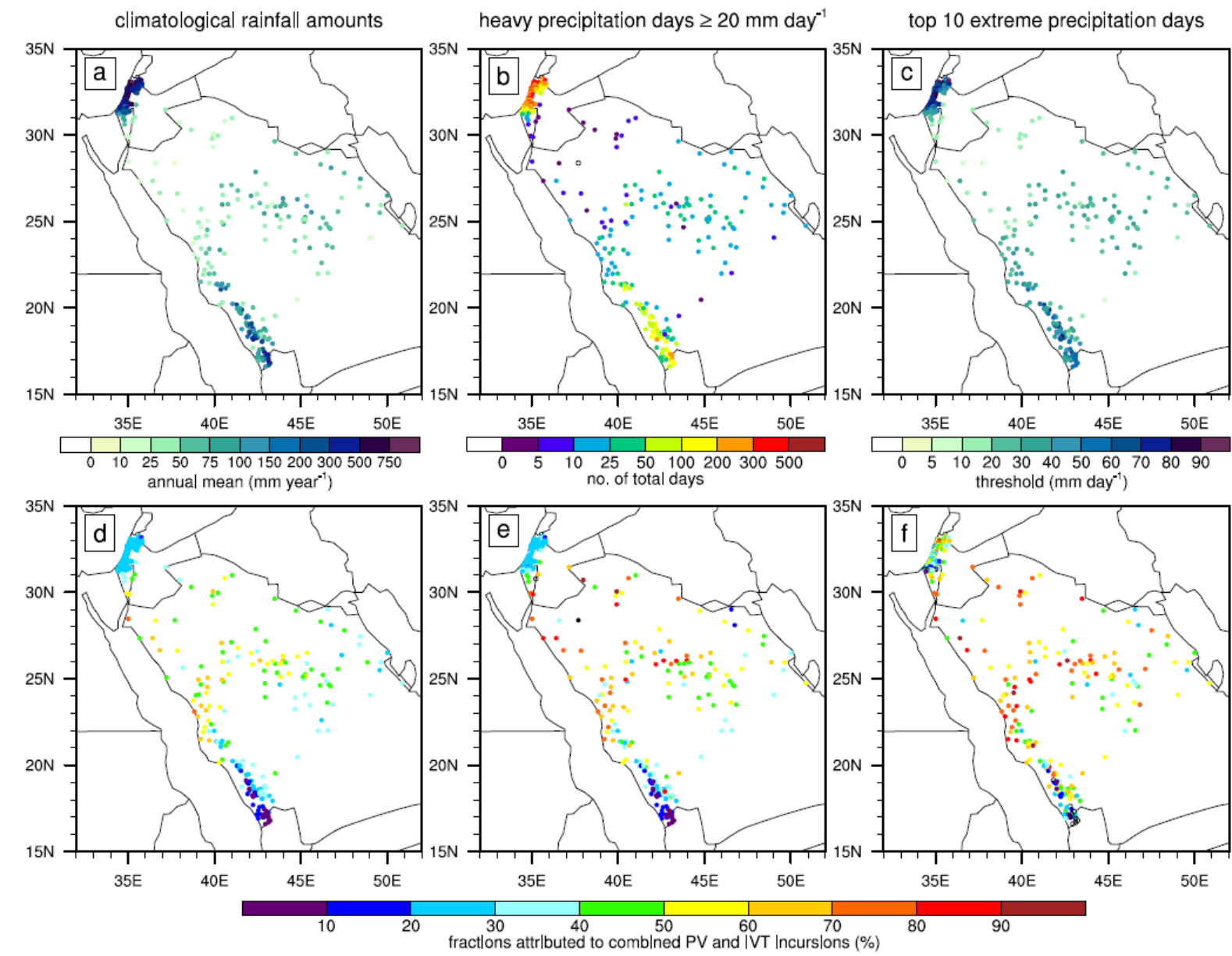

Figure 10. For rainfall observations of stations in Saudi Arabia (1979-2012) and Israel (1979-2015), the (a) annual mean precipitation amounts $\left(\mathrm{mm} \mathrm{year}^{-1}\right)$, (b) total number of heavy precipitation days with $\geq 20 \mathrm{~mm} \mathrm{day}^{-1}$, and (c) the threshold of precipitation $\left(\mathrm{mm} \mathrm{day}{ }^{-1}\right)$ that corresponds to the top 10 extreme precipitation days, and in (d-f) their fractions (\%) that coincide with combined PV and IVT incursions. Black open circles in (b,e,f) denote zero values and black filled circles in (e) represent stations without any heavy precipitation day. 